Les Cahiers des dix

\title{
Origines et formes diverses du " destin manifeste " dans les Amériques : les Papineau et la United States Magazine and Democratic Review de Washington et New York The Origins and Different forms of 'Manifest Destiny": The Papineaus and the United States and Democratic Review of Washington and New York
}

\author{
Louis-Georges Harvey et Yvan Lamonde
}

Numéro 67, 2013

URI : https://id.erudit.org/iderudit/1024247ar

DOI : https://doi.org/10.7202/1024247ar

Aller au sommaire du numéro

Éditeur(s)

Les Éditions La Liberté

ISSN

0575-089X (imprimé)

1920-437X (numérique)

Découvrir la revue

Citer cet article

Harvey, L.-G. \& Lamonde, Y. (2013). Origines et formes diverses du « destin manifeste » dans les Amériques : les Papineau et la United States Magazine and Democratic Review de Washington et New York. Les Cahiers des dix, (67), 25-73. https://doi.org/10.7202/1024247ar
Résumé de l'article

Axées sur l'avènement du Canada et la survivance de la collectivité canadienne-française, les traditions historiographiques canadienne et québécoise ne font que peu de place aux idées républicaines et à la pensée continentaliste. Pourtant, la conception d'un fédéralisme continental ancrée dans le destin démocratique des peuples du Nouveau Monde représentait un pendant important de l'idéologie républicaine de Louis-Joseph Papineau. En effet, la correspondance entre Papineau et son fils Amédée démontre que les deux hommes n'envisageaient rien de moins que l'émergence d'une nouvelle nationalité colombienne à l'échelle du continent nord-américain. Le providentialisme démocratique et républicain des Papineau s'inspirait d'un courant nationaliste, voire impérialiste, dont les origines remontaient à l'époque de la fondation des colonies anglo-américaines, mais qui s'actualisa au début des années 1840 dans la United States and Democratic Review de John L. O'Sullivan. La pensée continentaliste a aussi inspiré une vision bien différente de l'avenir du Canada français, des idéologues catholiques et plus tard ultramontains imaginant un destin glorieux pour leur petit peuple catholique qui devait par son caractère moral et pieux, sauver les masses protestantes de leur matérialisme effréné. Cette deuxième vision continentale, associée à Rameau de Saint-Père et à Étienne Parent, serait elle-même tributaire de réflexions françaises sur l'Amérique formulées au cours des années 1850. De part et d'autre, ces diverses destinées pour les Canadiens et pour l'Amérique s'inspiraient d'un discours messianique, soulignant dans chaque cas le caractère providentiel de leur vision de l'histoire.
Tous droits réservés @ Les Éditions La Liberté, 2013
Ce document est protégé par la loi sur le droit d'auteur. L’utilisation des services d’Érudit (y compris la reproduction) est assujettie à sa politique d'utilisation que vous pouvez consulter en ligne. 


\section{Origines et formes diverses du « destin manifeste » dans les Amériques : les Papineau et la United States Magazine and Democratic Review de Washington et New York}

\section{Louis-Georges Harvey et Yvan Lamonde}

xées sur l'avènement du Canada et la survivance de la collectivité cana-
dienne-française, les traditions historiographiques canadienne et québé-
coise ne font que peu de place aux idées républicaines et à la pensée continentaliste. Fort critique de cet angle mort dans l'histoire des idéologies au Québec, l'ouvrage récent d'Yvan Lamonde et de Jonathan Livernois, Papineau : Erreur sur la personne, révèle que la conception d'un fédéralisme continental ancrée dans le destin démocratique des peuples du Nouveau Monde représentait un pendant important de l'idéologie républicaine de Louis-Joseph Papineau. En effet, la correspondance entre Papineau et son fils Amédée démontre que les deux hommes n'envisageaient rien de moins que l'émergence d'une nouvelle nationalité colombienne à l'échelle du continent nord-américain. Concrètement, ils imaginaient qu'elle se constituerait par l'extension graduelle de la fédération étatsunienne qui s’adjoindrait de nouvelles républiques établies par les colons des territoires "sauvages " de l'Ouest américain, ou celles fondées par les anciens sujets de l'Amérique du Nord britannique et de la fédération canadienne. Les écrits de Papineau sur la question sont d'autant plus frappants qu'ils anticipent la création d'une nationalité colombienne qui serait essentiellement anglo-saxonne et l'assimilation des Canadiens français dans ce grand ensemble républicain. Or, 
ces propos de Papineau, tenus au soir de sa vie, détonnent singulièrement par rapport au destin providentiel que d'autres annonçaient pour la nation canadiennefrançaise. Des idéologues catholiques et plus tard ultramontains imaginaient plutôt un avenir glorieux pour leur petit peuple catholique qui devait par son caractère moral et pieux, sauver les masses protestantes de leur matérialisme effréné. De part et d'autre, ces diverses destinées pour les Canadiens et pour l'Amérique s'inspiraient d'un discours messianique, soulignant dans chaque cas le caractère providentiel de leur vision de l'histoire. Le providentialisme démocratique et républicain de Papineau s'inspirait d'un courant nationaliste, voire impérialiste, dont les origines remontaient à l'époque de la fondation des colonies anglo-américaines, mais qui s'actualise au début des années 1840. L'idéologie du "Manifest Destiny » inspire alors un mouvement politique favorable à la croissance territoriale des États-Unis qui se concrétise par l'annexion du Texas (1845), la guerre contre le Mexique (1846-1848) suivie par l'annexion de la moitié de son territoire et, enfin, l'acquisition d'une portion non négligeable du territoire de l'Oregon.

Les idées de Louis-Joseph Papineau sur le destin glorieux des États-Unis remontent au moins jusqu'aux années 1820 et les suites de la crise de l'Union de 1823-1825. Dans une série de lettres à sa femme écrites en Europe, Papineau modifia sensiblement son opinion des sociétés européennes, et surtout de celle de l'Angleterre, qu'il considérait dorénavant comme des sociétés aristocratiques en proie à la corruption politique et en déclin. Au même moment, il exprime une nouvelle appréciation du caractère républicain des États-Unis et il considère que la république était appelée à devenir un jour une grande rivale de la Grande-Bretagne. Quelques années plus tard, dans une brochure publiée sous le couvert de l'anonymat, il prédit qu'un jour toute l'Amérique serait républicaine et caractérise les États-Unis comme la société la plus parfaite et la mieux réglée de la terre. Papineau assume ouvertement des positions républicaines au cours des années 1830 et saisit toutes les occasions de citer les institutions politiques de la République américaine en exemple. Le Parti patriote suit son chef dans cette tendance et les 92 Résolutions, bien qu'elles affirment la loyauté bas-canadienne, finissent par citer les États-Unis comme le modèle des institutions tant souhaitées dans la colonie et les seules qui conviendraient à un peuple du Nouveau Monde. Lors de la réaction aux résolutions Russell, Papineau encense de nouveau les institutions américaines dans son fameux discours de Saint-Laurent, citant de façon provocatrice les héros de la Révolution américaine. Il va plus loin comparant favorablement le règne du gouvernement fédéral sur les États à celui de la métropole sur ces colonies, citant également le processus d'admission des territoires et États à la fédération américaine. Par contre, Papineau s'arrête là, refusant d'appuyer l'annexion du Bas-Canada à la fédération américaine et envisageant plutôt une 
indépendance bas-canadienne dans un avenir proche. Il n'est certes pas question de nationalité colombienne ou américaine, ou de nouvelle culture démocratique et républicaine. Le discours de Papineau demeure pour l'essentiel un discours anticolonial, qui dénonce la domination politique de la métropole en invoquant les institutions libres de la République américaine. Quand il proclame que toute l'Amérique sera libre et républicaine, Papineau ne souhaite rien de plus que la fin du colonialisme européen sur le continent nord-américain ${ }^{1}$. Pourtant, quelques années plus tard, Amédée Papineau aborde déjà la possibilité de la création d'une grande fédération continentale en des termes très proches du "Manifest Destiny " américain et Louis-Joseph Papineau anticipe l'intégration du Bas-Canada dans une grande fédération continentale. L'échec des Rébellions et le climat de répression qui domine dans la colonie contribuent sans doute à pousser les exilés politiques tels Louis-Joseph et Amédée Papineau vers des positions annexionnistes, mais la forme de ce discours et sa persistance sur le long terme témoignent du caractère déterminant de leur contact avec un républicanisme radical en pleine ébullition au début des années 1840 . Sur ce point, le parcours américain d'Amédée permet d'expliquer comment il aurait pu devancer et aussi influencer les idées de son père sur le républicanisme américain et le destin des États-Unis. La présence des exilés politiques bas-canadiens dans les États du Nord-Est américain rappelle l'importance de situer les Rébellions dans la perspective d'un affrontement entre les idéologies républicaine et monarchique qui a une portée continentale et qui doit être abordée dans une perspective transnationale. Le discours de l'époque ne manquait pas de souligner la nature essentiellement révolutionnaire du républicanisme américain dans un contexte colonial et pour certains auteurs américains les Rébellions canadiennes s'inscrivaient logiquement dans la suite de leur révolution. L'expérience des exilés et leur mouvement anticolonial alimentent donc un discours qui transformait le républicanisme américain et le mettait au service d'un nationalisme agressif et expansionniste. Le providentialisme de l'idéologie du Manifest Destiny permit de projeter la république sur l'ensemble du continent et d'imaginer la création d'un homme nouveau, dont le caractère essentiellement démocratique représenterait la dernière évolution de l'esprit humain.

1. Sur la pensée de Papineau dans les années 1820 voir : Yvan Lamonde, "Britannisme et américanité de Louis-Joseph Papineau à l'époque du deuxième projet d'Union (1822-1823) ", Les Cahiers des Dix, 66 (2012), p. 55-94 et Louis-Georges Harvey, Le Printemps de l'Amérique française, Montréal, Boréal, 2005, p. 102-103. Sur son discours républicain au cours des années 1830 voir: Yvan Lamonde, Histoire sociale des idées au Québec, 1760-1896, Montréal, Fides, 2000, p. 208-223 et Harvey, op. cit, p. 168-191. Sur la réponse aux Résolutions Russell et le discours de Saint Laurent voir : Louis-Georges Harvey, « Louis-Joseph Papineau » dans : D. Monière et R. Comeau [dir], Histoire intellectuelle de l'indépendantisme québécois, vol. I, Montréal, VLB, 2010, p. 40-50. 


\section{Les origines de l'idéologie du « destin manifeste » des États-Unis}

Les historiens américains font remonter les origines de l'idéologie du « destin manifeste » des États-Unis aux premières années de la colonisation européenne de la Nouvelle-Angleterre par les puritains. La migration des dissidents religieux anglais prend de l'ampleur à la fin des années 1630 et près de 20,000 puritains passeront en Amérique pour fuir la persécution exercée contre leur culte par les autorités royales anglaises. Libres d'exercer leur religion dans les colonies de Massachusetts Bay, du Connecticut et du Rhode Island, les puritains imaginent qu'ils établissent une nouvelle utopie religieuse en terre américaine. La colonisation acquiert un caractère providentiel puisque les puritains croient qu' elle représente la concrétisation de la volonté de Dieu. Même si le mysticisme des premières générations s'estompe à la fin du XVII e siècle et que plusieurs communautés puritaines abandonnent la foi de leurs pères, l'idée de l'Amérique comme terre de salut spirituel ne disparait jamais tout à fait. Un vent de renouveau évangélique souffle sur les colonies anglo-américaines au cours des années 1730 et 1740 et ce mouvement charismatique connu sous le nom de "First Great Awakening" a son pendant théologique dans les écrits de Jonathan Edwards, prédicateur de la Nouvelle-Angleterre dont les livres sur le mouvement américain auront un retentissement jusque dans la métropole. Pour Edwards, il n'y avait aucun doute que le renouveau spirituel de l'humanité se manifesterait d'abord dans le Nouveau Monde et qu'il entraînerait l'Europe dans son sillage. Edwards ira jusqu'à prédire qu'un jour le soleil se lèverait à l'ouest, mais l'importance de l'évolution de l'idée d'un destin providentiel des colonies anglo-américaines réside dans son élargissement du concept qui permettra d'intégrer tous ses habitants et des événements purement profanes à sa prophétie sur l'imminence d'une nouvelle ère de grâce religieuse. Ainsi, même si Edwards décède en 1759, ses successeurs verront dans la conquête de la Nouvelle-France par les armes britanniques un autre signe du destin providentiel des Anglo-américains, appelés à effectuer la rénovation du continent tout entier. La croissance rapide des colonies anglaises qui comptent près de deux millions d'habitants en 1760 et occupent tout le littoral atlantique de la Floride à la Nouvelle-Écosse semble leur donner raison. Ainsi, le concept d'un dessein providentiel lié à la colonisation américaine et la croissance territoriale étaient déjà liés dans la pensée américaine bien avant la Révolution ${ }^{2}$.

2. Anders Stephanson, Manifest Destiny. American Expansionism and the Empire of Right, New York, Hill and Wang, 1995, p. 13 ; Nathan O. Натсн, "The Origins of Civil Millennialism in America : New England Clergymen, War with France and the Revolution ", William and Mary Quarterly, Third series, XXXI, n 3, juillet 1974, p. 407-430. 
Lesprit de renouveau spirituel qui anime la pensée des théologiens puritains serait une des composantes de l'héritage intellectuel de la génération révolutionnaire, dont le républicanisme tient aussi de l'inspiration de l'histoire romaine et des Lumières françaises. L'histoire de Rome renforce l'idée que la Révolution jetterait les fondements d'une nouvelle civilisation sur les ruines de l'Empire britannique en déclin. Les Lumières promettaient un renouveau de l'esprit humain émergeant d'une longue nuit marquée par le fanatisme religieux et l'absolutisme. Selon Thomas Paine, dont la brochure Common Sense connut une grande popularité dans les premiers mois de la Révolution, les Américains devaient saisir l'occa-

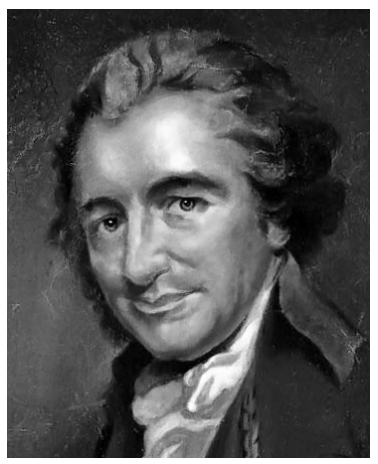

Thomas Paine (1737-1809), philosophe et publiciste dont les écrits ont influencé la pensée américaine. (Source : Google) sion qui leur était présentée, car en créant un gouvernement populaire ils entreprenaient une refonte globale de la société : "The birthday of the world is at hand " proclama-t-il. Quelques mois plus tard, les premiers paragraphes de la Déclaration d'indépendance de Jefferson annonçaient au monde entier l'intention des Patriots de réorganiser leurs gouvernements sur le principe radical de l'égalité des droits (pour les hommes blancs évidemment), de se dresser contre l'ordre monarchique et de mettre fin à la domination européenne sur les plus prospères colonies du Nouveau Monde. À la mission providentielle des puritains s'ajoutait donc une dimension politique et sociale qui ne faisait que confirmer le dessein providentiel et celui plus particulier de l'Amérique ${ }^{3}$.

Évidemment, le républicanisme classique comportait aussi certains empêchements relativement à la possibilité de la croissance illimitée de la petite fédération de républiques qui voit le jour en 1776. D’ailleurs, plusieurs républicains américains, convaincus que l'étendue de la fédération et le pouvoir trop concentré du gouvernement central menaceraient la liberté, tentent de miner la fédération, qui se trouve dans une impasse au milieu des années 1780. La Constitution des États-Unis, adoptée en 1787 à Philadelphie et ratifiée par les États dans les années qui suivent, propose une solution à cette impasse. Selon les fédéralistes qui en font la promotion, la constitution permet d'unir les petites républiques que sont les États tout en conservant leur autonomie par la création d'un système de contrepoids au cœur de la législature fédérale. Loin de constituer une menace à la stabilité politique de la République, la croissance territoriale permettrait de

3. Brian Loveman, No higher law: American foreign policy and the Western Hemisphere since 1776, Chapel Hill, University of North Carolina press, 2010, p. 56. 
mieux équilibrer les intérêts divers à l'intérieur de la fédération. Ainsi, Alexander Hamilton explique que la constitution fédérale proposée en 1787 allait " réprimer les factions et assurer la tranquillité intérieure des États... " et accroitre «... leurs forces et leur sécurité... » ${ }^{4}$. Autre promoteur de la Constitution, James Madison renchérit en prédisant qu'un plus grand nombre d'États dans la fédération neutraliserait l'influence des factions en multipliant les intérêts concurrents au sein du gouvernement central. Plutôt que d'affaiblir la république, comme le prédisaient les auteurs classiques et les sages des Lumières tel Montesquieu, Madison croit que la croissance de la fédération deviendrait le gage de sa stabilité politique :

Étendez sa sphère, elle comprendra une plus grande variété de partis et d'intérêts, vous aurez moins à craindre de voir à une majorité un motif commun pour violer les droits des autres citoyens, ou, s'il existe un tel motif commun, il sera plus difficile à ceux qui l'éprouvent de connaître leur propre force et d'agir de concert.

Le fédéralisme américain devenait donc un élément important d'une idéologie axée sur le renouveau politique et la croissance des États-Unis dans les décennies qui suivent l'adoption de la constitution en 1789 donne raison aux architectes du pacte fédéral : la fédération américaine compte 24 États en $1830^{5}$.

En effet, cette expansion rapide ne manque pas de contribuer à un sentiment national américain en plein essor au cours des années 1820. La commémoration du cinquantième anniversaire de la Déclaration d'indépendance en 1826 marque les esprits et alimente les mythes et la symbolique associés à la Révolution. Au même moment paraissent les premières véritables histoires de la Révolution qui

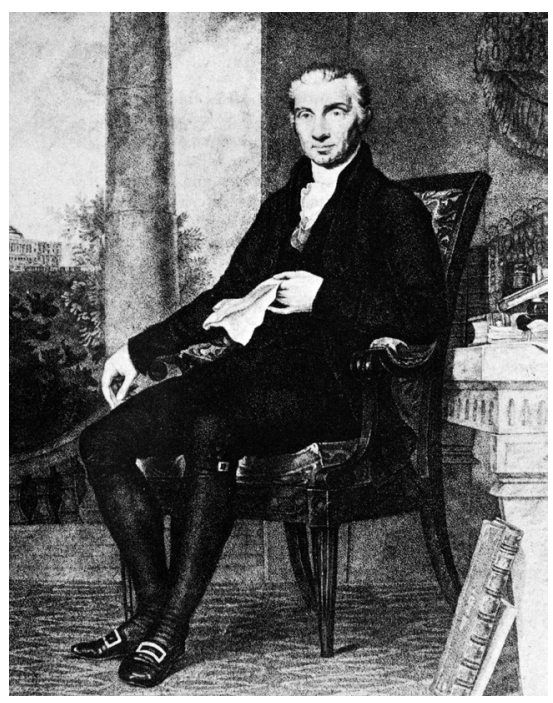

James Monroe (1758-1831), cinquième Président des États-Unis qui a donné son nom à la doctrine annonçant la fin de la colonisation européenne en Amérique. (Source: An Outline of American History, 1963)

4. Alexander Hamilton, «Le Fédéraliste, № 9 », dans : Alexander Hamilton, John Jay et James Madison, Le Fédéraliste, Nouvelle édition française avec une introduction bibliographique et historique par Gaston JĖZE, Paris, Giard et Brière, 1902, p. 60.

5. James Madison, «Le Fédéraliste , No 10 ", dans : Alexander Hamilton, John Jay et James Madison, Le Fédéraliste, op. cit, p. 75 ; Thomas R. Hietala, Manifest Design. American Exceptionalism and Empire, Ithaca, Cornell University Press, 2003 (1985), p. 175. 
soulignent son importance globale et son rôle historique dans la marche de l'humanité vers la liberté. Une nouvelle appréciation de la vocation géopolitique des États-Unis inspire également le président James Monroe qui, secondé par son secrétaire d'État John Quincy Adams, proclame en 1823 sa doctrine sur la noningérence des pouvoirs européens dans les affaires des nations du Nouveau Monde. La doctrine Monroe établit en effet un protectorat moral des États-Unis sur les républiques naissantes de l'Amérique latine, rejetant explicitement l'ingérence européenne :

[...] quant aux gouvernements qui ont déclaré leur indépendance, qui l'ont maintenue, et dont nous avons reconnu l'indépendance, après sérieux examen, et sur des justes principes, nous ne pourrions voir l'intervention d'une puissance européenne quelconque dans le but de les opprimer ou de contrarier d'une manière quelconque leur destinée, que comme la manifestation d'une disposition inamicale à l'égard des États-Unis .

Même si les États-Unis demeurent une puissance secondaire incapable d'exercer le rôle de policier en Amérique du Sud dans l'éventualité d'une intervention européenne, la déclaration du Président démontre que les Américains associent leur système de gouvernement républicain et démocratique à l'ensemble de l'hémisphère et qu'ils rejettent définitivement les régimes politiques européens.

\section{La concrétisation de l'idéologie du destin manifeste des États-Unis dans les années 1830 et 1840}

Les deux mandats consécutifs du président Andrew Jackson (1829-1837) et le radicalisme du discours de certains de ses partisans provoquent un bouleversement du contexte politique aux États-Unis. L'État de New York, souvent cité en exemple par la presse bas-canadienne des années 1830, est particulièrement secoué par ces transformations ${ }^{7}$. Le rôle important du parti new-yorkais dans les succès électoraux du Democratic Party à l'échelle nationale incite même Jackson

6. "Message adressé par le président Monroe au Congrès des États-Unis », 2 décembre 1823, traduit et reproduit sur Digithèque de matériaux juridiques et politiques. ( http ://mjp. univ-perp.fr/textes/monroe02121823.htm ), consulté 25 juillet 2013.

7. Sur le recours à l'exemple de l'État de New York dans le discours des Patriotes voir : L.-G. Harvey, Le Printemps de l'Amérique française, op. cit., p. 45-47, 111, 113-116, 152, 163-164, 177. 
à choisir Martin Van Buren comme colistier lors des présidentielles de 1832. La nomination de Van Buren assure au parti l'appui de la puissante machine électorale responsable des succès électoraux des Democrats au niveau de l'État et du long règne de William Marcy comme gouverneur. Pionnier de la nouvelle pratique d'assurer que ses partisans soient récompensés par des postes importants dans l'administration publique, Marcy n'hésite pas à s'associer aux banquiers et spéculateurs qui profitent de la croissance fulgurante de son État ${ }^{8}$. En réaction, une faction non négligeable du parti dénonce la spéculation et l'apparente alliance entre l'argent et le gouvernement, pointant du doigt la "moneyed aristocracy", dans un discours qui, encore une fois, a eu des échos dans la presse bas-canadienne. Pour cette aile radicale du parti, la taille des gouvernements doit se limiter au strict minimum requis pour assurer les droits des citoyens, il n'est pas question que l'État intervienne dans l'économie ou qu'il favorise certains entrepreneurs par des politiques protectionnistes ou en octroyant des monopoles. Pour ce qui est de la politique monétaire, les radicaux suivent l'exemple du président Jackson qui s'était attaqué aux grandes banques et surtout à la banque centrale des ÉtatsUnis, l'exemple le plus en vue d'une alliance contre nature de l'argent et du pouvoir politique. La querelle de Jackson avec les directeurs de la banque se transforme en croisade lors de sa deuxième campagne à la présidence et après sa réélection Jackson abolira la banque centrale, distribuant les actifs gouvernementaux à un certain nombre de plus petites banques opérant au niveau des États, récompensant du même coup quelques amis du régime qui étaient actionnaires des institutions qui profitent de la nouvelle politique fédérale. Quoi qu'il en soit, les radicaux continuent leur croisade contre les banques et l'aristocratie de la richesse, et celleci s'intensifie au moment de la "Panique de 1837 ", crise financière qui affecte justement les banques, dont plusieurs feront faillite au détriment des artisans et agriculteurs qui leur avaient fait confiance. New York devient le foyer principal de cette contestation, et dans la capitale new-yorkaise, les artisans et ouvriers tentent de déstabiliser le parti en votant des résolutions radicales pour éliminer tout lien entre le gouvernement et les banques. Prenant le nom de Loco Focos, ils avancent un discours républicain radical, très critique de la concentration du pouvoir politique et économique qu'ils associent au développement rapide de l'économie américaine. Sur le rôle du gouvernement et le danger de la concentration du pouvoir économique, les radicaux reviennent aux idées de Thomas Jefferson et des pères fondateurs et rêvent de recréer une république peuplée de

8. Ivor Debenham Spencer, The Victor And the Spoils : a Life of William L. Marcy, Providence, Brown University Press, 1959 ; Robert V. Remini, "The Albany Regency ", New York History, XXXIX, no 4, octobre 1958, p. 341-355. 
petits propriétaires terriens. Égalitaristes, démocrates et profondément républicains, les Loco Focos n'iront pas jusqu'à condamner l'esclavage. Pour ce qui est de la politique extérieure, ils s'opposent aux monarchies européennes et vouent une antipathie très marquée à la Grande-Bretagne?

Le radicalisme qui couve sous l'ère jacksonienne s'anime donc au moment de la crise économique de 1837 et provoque une évolution du discours sur le destin historique et même providentiel des États-Unis. Parmi les écrivains influencés par le radicalisme des Loco Focos se retrouve un jeune homme récemment diplômé de l'Université Columbia, John L. O'Sullivan. Disciple de Jefferson et de Madison, et fin connaisseur des auteurs fétiches de la tradition républicaine, O’Sullivan est lié au Democratic party et sa famille entretient des rapports étroits avec le président nouvellement élu Martin Van Buren. O'Sullivan pratique d'abord le métier de rédacteur à la barre du Washington Metropolitan, journal qu'il dirige avec son beau-frère William Langtree. L'idée de fonder un nouvel organe au service du Democratic party prend forme au lendemain de la victoire très serrée de Van Buren sur les candidats du parti Whig, William Henry Harrison et Hugh L. White. Malgré la grande popularité du Président sortant Andrew Jackson, Van Buren avait perdu des appuis dans les États esclavagistes du Sud et dans d'autres secteurs habituellement très

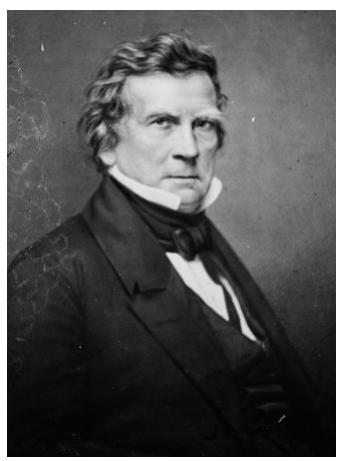

William Marcy (1786-1857), gouverneur de l'État de New York à l'époque des Rébellions de 1837 et 1838. (Source : Google)

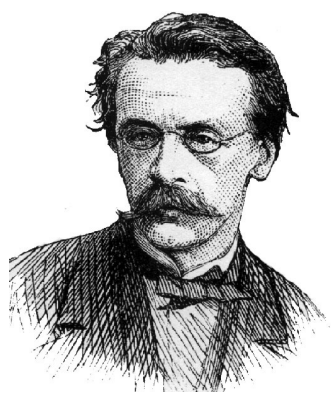

John L. O'Sullivan (1813-1895), homme politique et journaliste américain. (Source : Google) fidèles aux Democrats. Dans le contexte de la crise financière qui secoue le pays en 1837 , l'administration sent le besoin de préciser sa politique et cherche à créer un organe politique capable de la communiquer aux électeurs. Or, O'Sullivan et sa famille tentaient simultanément de se faire indemniser pour la mort de John O'Sullivan père qui avait agi, selon sa veuve, en tant que représentant des ÉtatsUnis au moment de sa mort en Amérique du Sud. Van Buren voit donc l'occasion de faire d'une pierre deux coups : il rembourse la dette due à la famille et enjoint

9. Robert V. Remini, Andrew Jackson and the Course of American Freedom, 1822-1832, New York, Harper \& Row, 1981 et R. V. Remini, Andrew Jackson and the Course of American Freedom, 1833-1845, New York, Harper \& Row, New York, 1984 ; Sean Wilentz, The Rise of American Democracy : Jefferson to Lincoln, New York, W. W. Norton, 2008, p. 219-240. 
au jeune John L. O'Sullivan de créer une revue au service des intérêts de l'administration.

Forts de cet appui en plus haut lieu, O’Sullivan et Langtree délaissent le Metropolitan et fondent la United States Magazine and Democratic Review à l'automne de $1837^{10}$. Dès le départ, la Review se distingue des journaux de l'époque en adoptant le format d'une revue politique et littéraire, calqué sur le modèle de la Westminster Review. Si son format s'inspire de la revue britannique, la Democratic Review se donne la mission de représenter le caractère essentiellement démocratique de la culture et de la politique des États-Unis et ainsi de mettre en lumière le génie particulier du peuple américain. La formule attire l'intérêt des philosophes et littéraires américains, et O'Sullivan convainc les plus importants auteurs de son époque, dont Ralph Waldo Emerson, Henry David Thoreau, Herman Melville et Nathaniel Hawthorne d'assurer le succès de la mission démocratique de la Review en y publiant des textes ${ }^{11}$. Pour les historiens, la Democratic Review représente d'abord la source de l'élaboration et de la première énonciation du concept de "manifest destiny", se référant à une formulation très claire du concept dans un texte de 1845 publié sous le titre "Annexation", et dans lequel O'Sullivan proclame " the fulfillment of our manifest destiny to overspread the continent allotted by Providence for the free development of our yearly multiplying millions ${ }^{12}$. "L'expression entre rapidement dans le discours politique lors des débats au Congrès sur la situation du Texas, portant plusieurs historiens à insister sur le rôle de John L. O'Sullivan et de sa Democratic Review ${ }^{13}$. Par contre, si cet article de 1845 consacre l'expression manifest destiny, l'idée du destin providentiel des États-Unis dans la marche historique de la démocratie se voit développée dans la Democratic Review dès ses premiers numéros et souvent dans des textes qui traitent de la situation politique du Bas-Canada.

10. Sur les origines d'O'Sullivan et la fondation de la Democratic Review, Robert SAmpson, John L. O'Sullivan and his Times, Kent (Ohio), Kent State University Press, 2003, p. 4-22.

11. Robert J. Scholnick, «Extermination and Democracy : O’Sullivan, the Democratic Review, and Empire, 1837-1840", American Periodicals, vol. 15, n 2, 2005, p. 125-126.

12. John L. O'Sullivan, "Annexation", United States Democratic Review (USDR), XVII, $\mathrm{n}^{\text {os }} 85-86$, juillet-août 1845 , p. 5 .

13. R. J. Scholnick, loc. cit., p. 128 ; T. R. Hietala, op. cit. p. 184 ; B. Loveman, loc. cit., p. 59. Robert W. Johannsen, "The Meaning of Manifest Destiny », dans : W. Johannsen [dir.], Manifest Destiny and Empire : American Antebellum Expansionism, Arlington, Texas A\&M University Press, 1997, p. 9-12. 


\section{La Democratic Review et la situation bas-canadienne}

Fondée à l'automne de 1837 pour faire avancer la cause de la démocratie américaine et confronter les systèmes monarchiques, la Democratic Review se voit rapidement aux prises avec le colonialisme européen, et ce dès l'éclatement des rébellions canadiennes à peine quelques semaines après la parution de son premier numéro, ce qui place la revue devant une situation délicate. Malgré un élan de sympathie dans la population des États du Nord-Est de la fédération, l'administration du président Martin Van Buren, craignant la guerre avec la Grande-Bretagne, proclame une stricte neutralité, interdisant aux citoyens américains de s'ingérer dans la situation canadienne sous peine d'emprisonnement. La politique de l'administration est à ce point impopulaire dans l'État de New York que le gouverneur William Marcy se voit obligé d'intervenir plusieurs fois pour limiter l'activité des citoyens qui se joignent aux patriotes hautcanadiens. La politique répressive du gouverneur le rend très impopulaire auprès de son électorat et, malgré sa puissante machine électorale, Marcy subit la défaite aux élec-

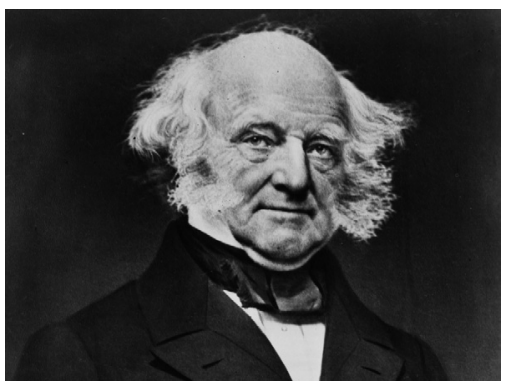

Martin Van Buren (1782-1862) septième Président des États-Unis. (Source : Google) tions de $1838^{14}$.

Pour sa part, O'Sullivan et sa Democratic Review doivent défendre la position de l'administration Van Buren, et ce malgré des sympathies évidentes pour la cause des rebelles et particulièrement pour celle des patriotes du Bas-Canada, que la revue juge beaucoup plus sérieuse que celle du Haut-Canada. Le premier texte sur les incidents paraît en janvier 1838 sous le titre, "The Canadian Question ». Larticle tente de mettre en contexte la situation bas-canadienne et reproduit de larges extraits des 92 Résolutions et des Résolutions Russell, jugeant que les confrontations armées de l'automne de 1837 étaient le résultat direct du refus de la métropole d'accéder aux demandes raisonnables des Patriotes. Le texte fait plusieurs rapprochements entre le mouvement politique bas-canadien et celui des Patriots américains qui s'étaient soulevés contre la métropole en 1776. Pour O'Sullivan, il devenait évident que le règne de la Grande-Bretagne sur ses colonies nord-américaines tirait à sa fin, puisque la majorité des Bas-Canadiens s'opposaient à la politique de la métropole et que l'idée de maintenir la colonie par l'usage de la force devenait impensable pour un pays aussi libéral que la Grande-Bretagne.

14. R. SAMPSON, op. cit., p. 57 ; I. D. SPENCER, op. cit., p. 99-100. 
Les Canadiens désiraient ardemment la liberté politique et ils ne pouvaient plus se contenter d'un régime colonial alors qu'ils avaient sous les yeux l'exemple de la République américaine et de ses citoyens libres. Ils n'accueilleraient plus à bras ouverts des aristocrates anglais venus d'outremer les gouverner et leur liberté politique ne dépendait plus que de leur volonté de rompre le lien colonial. Dans cette analyse, on comprend bien que l'éditeur se garde d'en appeler à une intervention directe des citoyens américains ou de leur gouvernement dans les affaires des colonies britanniques. Bien au contraire, même s'ils devaient se sentir contraints moralement de sympathiser avec la cause des Patriotes, et l'éditeur ne doutait pas que la majorité de ses concitoyens souhaitaient l'indépendance des colonies canadiennes, O'Sullivan insiste sur le fait que le sort du Bas-Canada dépendait des Canadiens.

Cependant, tout en défendant la position du gouvernement fédéral et en niant que les États-Unis convoitaient le territoire canadien, O'Sullivan saisit justement l'occasion pour exprimer une opinion sur l'avenir de la République. Évidemment, la question de l'annexion du Texas, en suspens depuis la demande d'admission du territoire en 1836 et le refus subséquent du gouvernement américain, inspire indirectement le commentaire qu'il fait sur la question canadienne. Lors des débats sur l'annexion du Texas, plusieurs critiques avaient soulevé la vieille question de l'étendue que pouvait avoir un gouvernement républicain, même dans une forme fédérale comme celle des États-Unis. Commentant la question canadienne, et tout en niant

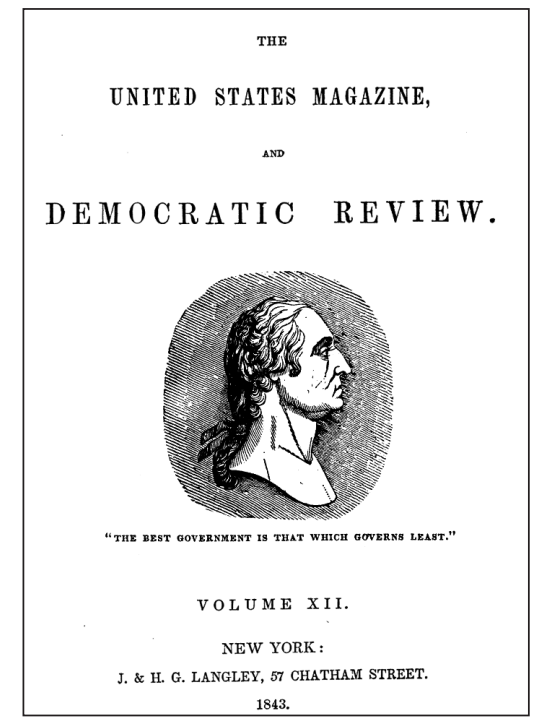

Page de titre de la Democratic Review, éditée par John L. O'Sullivan. (Source : Google) qu'il souhaitait l'annexion des colonies canadiennes, O'Sullivan profite de la situation pour exposer ses idées sur l'adhésion volontaire à la fédération étatsunienne des peuples émergents de la tutelle européenne. Pour O’Sullivan, le système fédéral américain se prêtait admirablement à l'expansion territoriale en garantissant l'autonomie et le respect des intérêts particuliers des États membres de la fédération. Le rôle du gouvernement fédéral se limitait à assurer une certaine uniformité des lois et à protéger les intérêts des États membres sur le plan de la politique internationale et de la sécurité, mais ce rôle devait s'exercer dans le respect de la Constitution et de 
l'équilibre qu'il établissait entre les deux paliers de gouvernement. Ainsi, même si l'auteur demeurait incertain quant au bien fondé d'annexer les colonies canadiennes ou encore d'accepter leur demande éventuelle de se joindre à la fédération, il demeurait persuadé que le système politique américain s'étendrait un jour sur tout le continent nord-américain : "we can see no reason why, at some future day, our experiment should not be in successful operation over the whole North American continent, from the isthmus to the pole ${ }^{15}$. "La rébellion bas-canadienne fournit donc l'occasion au rédacteur de la Democratic Review de formuler pour la première fois ses idées sur le destin providentiel des États-Unis et sur l'extension continentale du républicanisme.

Quelques mois plus tard, la Democratic Review publie un long texte divisé en deux parties intitulé " History of the Recent Insurrection in the Canadas ». Tiré principalement de sources journalistiques américaines et canadiennes, que l'éditeur n'hésite pas à critiquer, l'article offre une narration des principaux développements dans les deux colonies canadiennes, s'arrêtant longuement sur les événements survenus au Bas-Canada entre octobre et décembre 1837. L’analyse de la revue américaine s’inscrit dans le même courant de pensée que son premier texte sur la question canadienne, et O'Sullivan souligne à plusieurs occasions le caractère fondamentalement malhonnête, voire inhumain, des torys et royalistes de la colonie qu'il présente comme des hommes assoiffés de pouvoir et prêts à emprunter des moyens sanguinaires pour arriver à leurs fins. Les administrateurs et militaires britanniques prennent les allures de bureaucrates forcés d'imposer une raison d'État sur un peuple récalcitrant et après la prise d'armes ils le feront brutalement et sans pitié. Quant aux chefs patriotes et au peuple qu'ils représentent, la Democratic Review approuve leur mouvement « libéral » qu'il associe volontiers à celui des Patriots de 1776 et à ceux des peuples coloniaux du Nouveau Monde. L'auteur se montre toutefois critique quant aux tactiques des principaux leaders patriotes sur le plan militaire.

Quant à la diffusion internationale des événements lus dans une perspective plus sympathique aux Patriotes, cet article est d'une importance capitale. Il aurait alimenté la presse américaine, qui aurait repris certains passages de son analyse sans toujours souscrire à l'interprétation globale. Le rédacteur de la Democratic Review ne remet aucunement en question l'explication des principaux leaders du mouvement selon laquelle le gouvernement aurait provoqué la confrontation armée. Par ailleurs, O’Sullivan revient souvent sur le rôle de la presse ultra tory

15. J. L. O’Sullivan, "The Canadian Question ", USDR, I, n 2, 1838, p. 205-220, citation p. 218. 
de Montréal et notamment du Montreal Herald qui auraient mené une campagne haineuse dénonçant les activités légales des Patriotes et en incitant le gouverneur Gosford à écraser le mouvement politique de la majorité bien avant l'automne de 1837. Pour O'Sullivan, les torys deviennent donc les principaux instigateurs de ce qu'il qualifie de "civil war ». Les journaux tories représentaient aussi cette confrontation armée comme une guerre entre les races du Bas-Canada, attribuant aux Patriotes de vieux stéréotypes remontant à la Révolution française, invoquant même la Terreur et ses principaux artisans. Cette rhétorique de la presse montréalaise aurait servi à justifier la répression brutale qui s'ensuivit. O'Sullivan note que les torys auraient essayé de montrer l'unanimité des anglophones en organisant à Montréal une réunion de marchands américains pour dénoncer les Patriotes. Par contre, il s'empresse de noter l'enthousiasme et la sympathie pour la cause canadienne qui s'exprimèrent rapidement et spontanément tout le long de la frontière. Dans les principales villes du Vermont et de l'État de New York, des comités d'appui à la cause des patriotes bas-canadiens s'organisèrent et ramassèrent argent, vivres et munitions pour venir en aide aux Patriotes ${ }^{16}$.

O'Sullivan prétend que devant les mandats d'arrestation émis contre leurs chefs et les préparatifs militaires du gouvernement, les Patriotes durent se résigner à se défendre. L'article fait le récit des batailles de Saint-Denis et de Saint-Charles, mais il note autant le manque de préparation de la population que le courage de ceux qui se dressent devant les troupes britanniques. Le désarroi de la population après la défaite de Saint-Charles et l'humiliation du mouvement politique alors que les troupes paradent à Montréal avec l'arbre de la liberté érigé lors de la grande assemblée de la Confédération des Six Comtés soulignent l'ampleur de la défaite. Pour l'auteur, la bataille de Saint-Eustache prend l'allure d'un massacre que les autorités auraient pu éviter s'ils avaient négocié avec les rebelles. L'armée de Colborne et les volontaires qui l'accompagnaient voulaient toutefois écraser toute résistance et ils se montrèrent sans merci à l'égard de Chénier et des Patriotes qui défendaient le village. Le rédacteur décrit également les événements qui mènent à la destruction de Saint-Benoît et des autres villages du comté frondeur. La cruauté du commandant britannique n'étonne guère O'Sullivan et il prédit que l'événement aura un impact important sur l'avenir du Canada, mais aussi sur la réputation de la couronne britannique :

He created a desert and called it peace! The insurrection was indeed suppressed, but Canada has not been strengthened to the British crown. Such events as these will hardly find a place in the proud pages of English history ; but deep, deep will

16. J. L. O’ Sullivan, « History of the Recent Insurrection in the Canadas - Part First », USDR, III, $\mathrm{n}^{\circ}$ 4, mars-juin 1838, p. 74, 77. 
they burn into the heart of her distant province, and the blood of these patriot martyrs, so profusely shed at the altar of royalty, on an American soil, will hallow their cause with millions of the free, and forever dishonor the escutcheon of England's Virgin Queen, with an ineffaceable stain of blood, which, in this hemisphere, at least, will link a name auspicious to all the rest of her empire, with the doings of the TYRANT KING who left his parricidal print of blood upon the American soil, to form the seal of its freedom to all future time. ${ }^{17}$

Le récit bifurque ensuite sur la situation du Haut-Canada et particulièrement sur les expéditions lancées des États-Unis pour enlever la province au contrôle britannique. Il est aussi question des tentatives des autorités américaines pour empêcher que la guerre n'éclate sur la frontière, et ce malgré les provocations des Britanniques. O'Sullivan raconte en détail l'incident du bateau à vapeur Caroline et les engagements à Navy Island, jugeant hasardeuses et vouées à l'échec les expéditions entreprises pour libérer le Haut-Canada. Il revient ensuite à la situation bas-canadienne pour décrire brièvement l'incursion de Robert Nelson en février 1838, n'y voyant, encore une fois, qu'une vaine tentative qui n'aurait eu que peu d'appuis dans la colonie. Pour O'Sullivan, ces événements prouvent la sympathie des Américains pour la cause canadienne et il avance que dans le cas d'un mouvement majoritaire et bien organisé des populations canadiennes, l'appui massif des voisins américains garantirait leur indépendance. Il n'en tenait donc qu'aux Canadiens de se soulever de façon déterminante et de saisir leur liberté :

however Britain may legislate, the hardy, simple, republican, people of the North, hold, at all times, the balance of power between her and her province in their hands, and that it rests, at any moment, with the Canadians themselves, to maintain the equipoise with European interests and European rulers, a cumbrous inutility of an irresponsible monarchy and its ten thousand alien bayonets or to make the scale preponderate, in a moment, with the priceless benefits of popular liberty, selfgovernment, and national independence, chiefly and lastingly secured. This is but anticipating the language of history, and is a question with which government and their interests can have little bearing.

En guise de conclusion, O'Sullivan reconnait que le soulèvement n'avait pas été préparé et que le gouvernement avait provoqué les Patriotes afin de mieux les écraser, une politique britannique déjà employée de façon encore plus brutale en Irlande. En dernière analyse, malgré que la cause des Patriotes ait été juste, ceux-ci seraient toujours jugés par l'histoire comme des rebelles ayant provoqué la rupture

17. J. L. O' Sullivan, "History of the Recent Insurrection in the Canadas - Part Second ", USDR, III, $\mathrm{n}^{\circ} 4$, mars-juin 1838, p. 94. 
de la paix sociale, un sort réservé aux vaincus ${ }^{18}$. Pour O'Sullivan, par contre, il parait clair qu'il ne s'agit que de partie remise.

Un troisième article de fond sur la «Canadian Question " paraît en janvier 1839, après la répression des tentatives de soulèvement de 1838 et de nombreux incidents le long de la frontière américaine et sur le territoire des colonies britanniques impliquant des citoyens de la république aidant ou combattant aux côtés des rebelles canadiens. Bien qu'il continue d'analyser la situation canadienne dans le contexte de l'évolution de la liberté politique en Amérique, O'Sullivan se voit obligé de prendre la défense de l'administration de Van Buren et de sa politique de neutralité. Il reconnait d'emblée l'impopularité des mesures prises afin d'assurer la non-ingérence des citoyens américains dans les affaires des colonies canadiennes et il constate que le mécontentement des citoyens favorables à la cause des Canadiens s'est fait sentir dans tous les États longeant la frontière canadienne et qu'elle aurait nui aux intérêts politiques des Democrats. Le rédacteur de la Democratic Review maintient toutefois que malgré l'impopularité de la politique adoptée par le gouvernement fédéral, celle-ci s’imposait pour des raisons de sécurité nationale et que dans ce contexte les intérêts supérieurs de la nation devaient prévaloir sur un "local current of excitement. " Le souci de veiller à ce que les citoyens américains respectent une neutralité stricte s'imposait par la nature même de leur gouvernement. La République étant l'expression institutionnelle de la volonté du peuple, chacun de ses citoyens devenait en quelque sorte un représentant de l'État et leurs gestes pouvaient ainsi rejaillir sur le gouvernement central. La non-ingérence dans les affaires canadiennes devenait un devoir citoyen et les violations de la loi fédérale devaient avoir des conséquences sérieuses qui ne pouvaient être pardonnées ou expliquées par les mérites de la cause en question, soit la liberté des Canadiens. Par ailleurs, O’Sullivan prétend que la politique du gouvernement Democrat s'inscrivait dans les grandes tendances de la politique extérieure des États-Unis telle qu'elle fut élaborée depuis la présidence de Washington. Les États-Unis avaient toujours cherché à préserver leur neutralité en respectant la souveraineté des autres nations et les traités signés avec des pays tels que la Grande-Bretagne.

O’Sullivan rejette toute critique voulant que la politique de Van Buren ait été motivée par la crainte d'une déclaration de guerre de la Grande-Bretagne contre les États-Unis. En effet, les adversaires de l'administration citaient la complaisance du gouvernement devant les activités des Américains au Texas comme un exemple de la lâcheté de sa politique à l'égard des rébellions canadiennes. Sur

18.

Ibid., p. 103-104. 
ce point, le rédacteur de la Review précise que l'administration Democrat d'Andrew Jackson avait invoqué les lois fédérales pour limiter les activités des citoyens américains au Texas. Selon O'Sullivan, la puissance britannique était en déclin et une déclaration de guerre contre les États-Unis aurait l'effet de provoquer la perte immédiate de toutes ses colonies en Amérique du Nord. Par ailleurs, le peuple britannique ne supporterait pas qu'on fasse la guerre aux colons américains pour conserver les privilèges de quelques administrateurs. Enfin, cette guerre serait futile puisque l'indépendance des colonies canadiennes était inévitable. En effet, les événements de 1838 rendaient la chose encore plus évidente qu'elle ne l'avait été au moment du premier commentaire de la Democratic Review sur la question canadienne. Il en conclut : "Canada is gone. The days of its subordinate connexion with Great Britain are numbered ${ }^{19}$. »

L'analyse de la revue sur la situation politique de la colonie paraît bien documentée et s'appuie fortement sur le témoignage de sources près des réfugiés patriotes. Ainsi, devant les accusations des torys montréalais sur le caractère ethnique des soulèvements, la Democratic Review cherche consciemment à rétablir les faits. Encore une fois, O'Sullivan remonte dans l'histoire du mouvement pour montrer d'abord qu'il ne regroupait pas exclusivement des Canadiens français. L'auteur note que la plupart des comtés anglophones de la colonie avaient voté avec la majorité dans les élections de 1832 et de 1834, que les anglophones participaient activement au mouvement politique ; il cite le cas de Wolfred Nelson qui fut impliqué lors des grandes assemblées de 1837 et devint un des héros de la résistance à l'agression britannique. La Democratic Review souscrit de nouveau à la version patriote des événements, insistant sur le fait que le mouvement n'avait absolument pas préparé une insurrection contre le pouvoir britannique, mais qu'il s'était plutôt borné à organiser une résistance légale et constitutionnelle devant la répression politique de la métropole.

O'Sullivan cherche également à réfuter ceux qui prétendaient qu'il était de l'intérêt des États-Unis de s'ingérer dans le conflit canadien. Il cible particulièrement le discours des réfugiés patriotes qui soutiennent que la répression politique et militaire pratiquée contre les colonies canadiennes faisait partie d'une stratégie britannique visant à déstabiliser la fédération américaine. Bien que sympathique à la cause, le rédacteur ne trouve aucune preuve à l'appui de cette thèse et il repousse vigoureusement l'idée que les Américains se doivent d'intervenir et d'annexer les colonies canadiennes afin de mettre fin à l'influence britannique sur le continent. Au contraire, il soutient que pour le moment l'annexion n'était guère

19. J. L. O’Sullivan, "The Canada Question ", USDR, V, nº13, janvier 1839, p. 19. 
souhaitable, ni pour les États-Unis, ni pour les Canadiens. Dans ce contexte, la politique de l'administration Van Buren était sans doute la plus sage. Évidemment, il fallait sympathiser avec la cause d'un peuple dont le mouvement d'affirmation politique s'inspirait des mêmes principes que la Révolution américaine et qui ne souhaitait que de se donner des institutions libres et populaires comme celles de la République, mais il incombait aux Canadiens de conquérir eux-mêmes leur indépendance, d'établir leur république et de faire leurs premiers pas en tant que nation libre. Pour O'Sullivan, le destin démocratique et indépendant des colonies canadiennes, et particulièrement du Bas-Canada, semblait la suite logique de l'histoire. Les vieilles institutions monarchiques et aristocratiques de l'Europe devaient inévitablement faire place aux institutions républicaines sur le continent nord-américain ${ }^{20}$.

L'interprétation générale des Rébellions qui se dégage des pages de la Democratic Review situe le combat des Canadiens dans le contexte d'un affrontement à long terme entre le despotisme monarchique européen et le républicanisme démocratique américain. La perspective géopolitique de ce grand mouvement revient constamment dans les textes d'O'Sullivan, et ses analyses ne manquent jamais l'occasion de mettre en opposition les régimes politiques qui s'affrontaient et les hommes qui les représentaient. Dans plusieurs articles sur le Bas-Canada, les principaux chefs patriotes reçoivent des éloges de la part d'O'Sullivan, qui leur trouve des qualités dignes des républicains nord-américains. Seulement quelques mois après l'arrivée de Louis-Joseph Papineau aux États-Unis, la Review publie un poème composé par " Miss A. D. Woodridge », institutrice et amie des Papineau lors de leur séjour à Albany. Les vers de madame Woodridge présentent Louis-Joseph Papineau aux lecteurs américains comme l'incarnation des aspirations de son peuple à la liberté politique, le destin du Bas-Canada étant de former un jour une nouvelle république, et sans doute, un nouvel État dans la fédération américaine :

Unwavering champion of thy countrys cause,

Shrink never from thy high and glorious task,

Till free, self-governed, from the strangers thrall

Released, a young Republic shall arise,

Star-crowned, amid the nations, and shall hail

With praise and blessing her tried patriots name ${ }^{21}$.

Papineau fait aussi l'objet d'un passage élogieux publié en marge d'un texte analysant les conclusions du Rapport de Lord Durham en 1839. Ici, l'auteur cherche

20. Ibid., p. 28.

21. Miss A. D. Woodridge, " Papineau ", USDR, III, nº 1, 1838, p. 112-113. 
à établir un contraste entre le chef patriote et les autorités britanniques, dont Durham lui-même, s'inspirant de sa propre connaissance de Papineau et des témoignages de certains politiques américains sur son caractère et ses principes. L'orateur bas-canadien serait un homme élégant, intelligent, sobre, intègre, généreux et transparent, possédant " an earnest patriotism - an incorruptible integrity, both of public and private character - all the severe virtue of a Cato, with a mind deeply imbued with the liberal political philosophy of the age... ". La note s'appuie sur le témoignage d'un Sénateur américain qui assurait que Papineau connaissait mieux que nul autre étranger l'histoire des États-Unis, ses principes politiques et les principaux enjeux de la politique américaine ${ }^{22}$. D'autres chefs bas-canadiens reçoivent aussi un traitement très favorable de la part de la Democratic Review, dont Wolfred Nelson, cité pour son intégrité, son courage et sa constance devant les persécutions des autorités britanniques ${ }^{23}$.

À l'encontre des chefs patriotes, O'Sullivan dépeint les autorités britanniques en aristocrates hautains et cruels tentant d'imposer un régime injuste par la force des armes. En ce sens, la Democratic Review présente Lord Durham à ses lecteurs comme un dictateur aristocratique entouré de gardes et de serviteurs qui gouvernait le Canada dans la pompe et le faste. Sous la plume d'O'Sullivan, l'envoyé spécial du gouvernement britannique devenait « a vice-regal dictator, with all the terrors and splendours of a despotism to awe and dazzle all men into submissive acquiescence with the acts of its irresistible will, guided by its infallible intelligence. » La mission de Durham devenait « Durham's mission of dictatorship » et la Review constatait que le retour précipité du gouverneur dans la métropole témoignait de l'échec de sa mission. Les circonstances entourant le départ de Durham et les insurrections de 1838 constituaient également de nouvelles preuves à l'appui de l'impossibilité de concilier les intérêts des Patriotes et ceux de la métropole. La seule option possible pour le gouvernement britannique était de se plier aux demandes du parti populaire et de concéder un Conseil législatif électif, voire d'accepter que le principe électif soit la seule base légitime de gouvernement en Amérique. O'Sullivan ne manque aucune occasion d'écorcher Sir John Colborne qu'il considère comme le bourreau de Saint-Eustache et auquel il reproche d'avoir mis à sac et à feu la campagne bas-canadienne ${ }^{24}$. La répression militaire de 1838 pratiquée contre les régions les plus frondeuses de la colonie inspire un nouveau poème, "Canadian Avatar ", publié après quelques extraits de journaux décrivant la destruction des villages bas-canadiens à l'automne de

22. J. L. O'Sullivan, "Lord Durham's Report ", USDR, V, 18, juin 1839, p. 547-548.

23. J. L. O’Sullivan, "The Canada Question", (1839), loc. cit. , p. 20-21.

24. Ibid., p. 18, 23. 
1838. L'auteur considère que les gestes des officiers et des soldats britanniques ne pouvaient que leur apporter de la honte : "CAN the warriors of England then glory in shame, And consent to seek laurels mid the cottages fire ? How the wail of the mother will trumpet their fame, And the shriek of the babe give their deeds to the lyre! » Le texte renferme aussi une rare critique de la politique de nonintervention des États-Unis devant un mouvement si clairement inspiré des mêmes principes que la Révolution américaine :

And America, too, on her pillow reclined,

Calmly folded her hands on her bosom of cold, As though the oppressed could no precedent find,

For spurning their chains like our fathers of old,

Rebellious are they who would govern themselves,

Rebellious are they who would scorn to be slaves,

Take down your bright volumes from History's shelves,

And open the seals of your forefathers graves... ${ }^{25}$

Un des derniers textes traitant en profondeur de la situation du Bas-Canada est publié en juin 1839 et consiste en une analyse poussée du Rapport de Lord Durham sur les affaires canadiennes. Le rédacteur de la Democratic Review adoucit quelque peu son jugement sur Lord Durham et il trouve matière à louanges dans des pages du rapport. Durham et ses conseillers auraient eu le mérite de souligner le caractère corrompu des régimes politiques en place dans les deux provinces et de préconiser des réformes propres à permettre aux coloniaux une plus grande autonomie et un meilleur contrôle sur les dépenses publiques. Par contre, même si le rapport mettait à jour de nombreuses instances de corruption et de favoritisme, O'Sullivan prétend que ces révélations ne représentent que le dixième des cas soulevés par les Patriotes et il souligne que Durham ne reconnait pas pleinement que cette corruption découlait essentiellement d'une domination de la population par une faction oligarchique. Par cette analyse, il endosse sans réserve la position des Patriotes bas-canadiens et il condamne non seulement le rapport Durham, mais aussi les journalistes américains qui ne voyaient dans les rébellions qu'une lutte de races. Durham utilisait cette interprétation pour banaliser le mouvement réformiste bas-canadien, mais selon O'Sullivan la participation importante des anglophones au sein du parti patriote, le caractère de son chef Louis-Joseph Papineau, et surtout son discours et ses tactiques politiques l'identifiaient comme essentiellement un mouvement anticolonial. ${ }^{26}$

25. "Canadian Avatar ", USDR, III, n 12, décembre 1838, p. 380-381.

26. J. L. O’Sullivan, "Lord Durham's Report ", loc. cit., p. 562. 
Dans l'ensemble, les commentaires de la Democratic Review sur la situation politique du Bas-Canada, sur les Rébellions de 1837-1838 et sur le Rapport Durham démontrent une grande sympathie pour la cause des Patriotes. D’abord, malgré la participation importante de citoyens américains aux tentatives d'invasion du Haut-Canada en 1838, la Democratic Review constate que le mouvement anticolonial du Bas-Canada était beaucoup plus développé et profitait d'un plus grand appui populaire. $\mathrm{La}$ Review considère aussi que le parti patriote et son chef Louis Joseph Papineau luttaient contre des abus semblables à ceux qui avaient mobilisé les Patriots américains, une position qui était

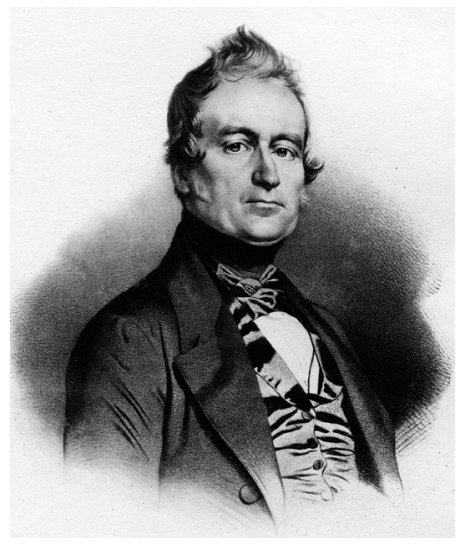

Louis-Joseph Papineau (1786-1871). (Source: Bibliothèque de l'Assemblée nationale) loin de faire l'unanimité dans la presse américaine de l'époque. Quant aux Rébellions, O'Sullivan n’hésite pas à soutenir la thèse d'une conspiration tory qui aurait poussé le gouverneur Gosford à imposer une répression militaire injustifiée par les actions des Patriotes afin de mieux étouffer la contestation du régime, une tactique déjà utilisée par les autorités britanniques, notamment en Irlande. Sur l'avenir du Bas-Canada, O’Sullivan rejette l'idée d'une intervention américaine dans les affaires de la colonie, mais il croit que le peuple du Bas-Canada ne pouvait récuser des positions républicaines et anticoloniales qu'il avait endossées en 1837. O'Sullivan inscrit donc la lutte dans le Bas-Canada dans le contexte d'un mouvement de libération coloniale amorcé en 1776 par la Révolution américaine. En effet, la situation canadienne fournit au rédacteur de la Democratic Review plusieurs occasions de développer sa pensée sur le caractère démocratique des sociétés du Nouveau Monde et sur le déclin inévitable des empires européens et des formes politiques aristocratiques qu'ils y perpétuaient. Ici, on reconnait que le progrès de la démocratie ne se ferait pas par l'intervention directe des États-Unis, mais plutôt par le progrès des idées républicaines et le pouvoir d'attraction des institutions politiques de la grande république.

\section{La Democratic Review et le providentialisme républicain}

Les historiens ont le plus souvent considéré l'idéologie du Manifest Destiny comme une forme romantique du nationalisme américain. Or, le nationalisme, pour reprendre les définitions de Benedict Anderson, se construit la plupart du 
temps sur une relecture de l'histoire qui cherche à retracer les origines de la nation, parfois dans un passé lointain, afin de mieux comprendre son caractère et les traits que lui aurait imposés sa trajectoire distincte. L'histoire nationaliste identifie la collectivité à un combat qui s'inscrit sur la longue durée contre des ennemis ou des circonstances qui entravent son développement. L'histoire permet aussi de donner un sens à la grande épopée nationale, de découvrir la mission historique de la nation et donc d'identifier son destin dans le déroulement de l'histoire mondiale ou humaine ${ }^{27}$. Les écrits de John L. O'Sullivan sur les rébellions canadiennes semblaient les inscrire dans la logique d'une trame historique à plus long terme dans les Amériques, mais ils n'abordaient pas directement la question du rôle des États-Unis dans cette histoire. On pouvait deviner que la République américaine servirait d'exemple aux divers peuples des Amériques, comme elle l'avait fait pour les Bas-Canadiens. Or, quelques mois après qu'O'Sullivan signe son dernier texte de fond sur la question canadienne, la Democratic Review publie un article intitulé «The Great Nation of Futurity " qui situe le destin des ÉtatsUnis dans une perspective continentale, voire mondiale, établissant simultanément les bases d'un nationalisme américain de nature messianique et entièrement conforme aux catégories établies par Anderson ${ }^{28}$.

La naissance du peuple américain forme le point de départ de ce texte et l'auteur avance que la particularité de la nation américaine se trouve justement dans l'hétérogénéité de sa population composée d'immigrants arrivés de différents pays d'Europe. La Déclaration d'indépendance et la Révolution américaine auraient transformé ces communautés disparates en leur permettant de former une nation basée non pas sur une longue histoire partagée ou des faits d'armes lointains, mais sur une adhésion commune au " great principle of human equality ». La fondation des républiques américaines et de la fédération qui constitue les États-Unis devenaient donc les premiers événements d'une nouvelle phase de l'histoire humaine :

our national birth was the beginning of a new history, the formation and progress of an untried political system, which separates us from the past and connects us with the future only; and so far as regards the entire development of the natural rights of man, in moral, political, and national life, we may confidently assume that our country is destined to be the great nation of futurity ${ }^{29}$.

27. Benedict Anderson, Imagined Communities: Reflections on the Origin and Spread of Nationalism, Londres, Verso, 1991, p. 194-195.

28. J. L. O'Sullivan, "The Great Nation of Futurity ", USDR, VI, n 23 , novembre 1839 , p. 426-430.

29. Ibid., p. 426. 
À l'encontre de l'histoire des régimes monarchiques marquée par de grandes croisades lors desquelles des hommes furent dupés et convaincus de s'entretuer au nom d'une dynastie ou d'une religion, celle des États-Unis se distinguait par des combats menés par des Patriots soucieux de défendre leur patrie et leur liberté politique. Les États-Unis représentaient donc le pays de l'avenir, celui qui réaliserait son destin providentiel en menant l'humanité vers la liberté.

La mission providentielle des États-Unis se résumait donc à la quête de la liberté et de l'égalité politique et le caractère universel de ces principes déterminait son rôle historique. En fait, l'auteur considère l'égalité politique comme essentielle au bonheur des peuples et celle-ci constituerait la base du patriotisme américain. Les États-Unis devenaient donc « the nation of human progress " dont la providence avait déjà tracé le destin historique :

The far-reaching, the boundless future will be the era of American greatness. In its magnificent domain of space and time, the nation of many nations is destined to manifest to mankind the excellence of divine principles; to establish on earth the noblest temple ever dedicated to the worship of the Most High, the Sacred and the True. Its floor shall be a hemisphere, its roof the firmament of the star-studded heavens, and its congregation an Union of many Republics, comprising hundreds of happy millions, calling, owning no man master, but governed by Gods natural and moral law of equality, the law of brotherhood of peace and good will amongst men. $[\ldots]$

... All this will be our future history, to establish on earth the moral dignity and salvation of man, the immutable truth and beneficence of God. For this blessed mission to the nations of the world, which are shut out from the life-giving light of truth, has America been chosen ; and her high example shall smite unto death the tyranny of kings, hierarchs, and oligarchs, and carry the glad tidings of peace and good will where myriads now endure an existence scarcely more enviable than that of beasts of the field. Who, then, can doubt that our country is destined to be the great nation of futurity ? ${ }^{30}$

Le caractère religieux de ces passages indique clairement que l'élaboration de l'idéologie du destin manifeste des États-Unis fait écho aux conceptions théologiques héritées du Great Awakening du XVIII ${ }^{\mathrm{e}}$ siècle, et d'une pensée millénariste renouvelée lors d'un grand mouvement d'enthousiasme religieux qui secoue de nouveau les États-Unis entre 1815 et 1840 . Le destin des États-Unis se voit donc imbu d'un caractère providentiel, la Révolution américaine constituant un événement charnière dans le déroulement de la volonté divine sur terre.

30. Ibid., p. 427. 
Il n'en demeure pas moins que la révélation annoncée par les Patriots américains s'incarnait dans la création d'un régime politique essentiellement démocratique et voué à l'assurance de l'épanouissement de l'individu, le "pursuit of happiness » de la Déclaration d'indépendance. Dans un texte simplement intitulé "Democracy ", O’Sullivan explique que l'avènement des régimes démocratiques n'est pas que la manifestation d'une volonté divine, elle représente également la dernière et ultime étape de l'évolution de pensée politique humaine, le triomphe de la raison, de la justice et des meilleurs principes de charité chrétienne. Pour le rédacteur de la Democratic Review, l'ultime victoire de la démocratie sur les régimes monarchiques ou aristocratiques ne fait aucun doute. Le triomphe des forces luttant contre la tyrannie, le privilège et le monopole et pour les principes de la justice, le progrès et la dignité humaine ne pouvaient échouer, car leur cause était celle de tous les hommes et les majorités étaient destinées à se gouverner. O'Sullivan juge que le gouvernement aristocratique ne pouvait tenir devant l'exemple d'un régime établi par le peuple pour défendre les intérêts de la majorité, car le despotisme devait nécessairement s'asseoir sur la force. Les classes privilégiées complotaient sans cesse afin de maintenir leur position ou pour se tailler une place plus grande aux dépens de la majorité. Elles empruntaient donc les tactiques de la corruption, la déception, la censure et la force des armes afin de se cramponner au pouvoir devant la marche inexorable des mouvements populaires, mais pour O’Sullivan la victoire de la démocratie demeurait inévitable. Dans les sociétés démocratiques, le rôle des gouvernements se résumait donc à protéger les citoyens de cette domination néfaste des élites aux ambitions aristocratiques. La vigilance était de mise, d'autant plus que le gouvernement luimême pouvait se prêter à cette domination s'il tombait entre les mains des minorités avares de pouvoir. Dans cette logique, l'accumulation des richesses et le luxe demeuraient suspects et O'Sullivan emprunte le vocabulaire jacksonien de «l'aristocratie des richesses " pour décrire la faction qui menaçait le plus la stabilité des institutions républicaines ${ }^{31}$.

La progression inévitable de la démocratie rendait tout aussi certaine la croissance territoriale de la fédération américaine. Au début des années 1840, de jeunes radicaux du parti Democrat le poussent vers des positions plus agressives quant à la politique extérieure et en particulier sur la question de l'annexion des territoires limitrophes où plusieurs citoyens américains se sont déjà installés. Le Texas vient en tête de cette liste et la question de son annexion éventuelle à l'union américaine faisait l'objet de vifs débats politiques depuis la rébellion de cet État mexicain et son érection en république indépendante. L’annexion du Texas domine

31. J. L. O’Sullivan, «Democracy ", USDR, VII, n 27, mars 1840, p. 215-229. 
l'élection présidentielle de 1844 et le candidat Democrat James Polk s'engage à intégrer la république texane dans l'Union et également à s'approprier le territoire de l'Oregon, contesté par l'Angleterre. L'élection de Polk avance la cause des "Young Democrats ", dont plusieurs se retrouvent maintenant au Congrès et elle met la question de l'annexion du Texas à l'agenda des travaux de la législature américaine $^{32}$. Bien qu'ils ne pouvaient appuyer l'annexion des colonies canadiennes en 1838 et 1839, O'Sullivan et sa Democratic Review appuient maintenant sans hésitation celle du Texas. Dans un article simplement intitulé "Annexation ", O'Sullivan exige que l'on cesse de débattre de la question, puisque les États-Unis avaient invité le Texas à se joindre à l'Union et les Texans avaient accepté. Il ne demeurait donc qu'à accueillir leurs représentants au sein du Congrès américain. Il s'agit aussi du texte où le rédacteur de la Review rend explicite sa pensée sur le Manifest Destiny et de celui qui consacre l'expression dans l'usage politique de l'époque. En fait, O'Sullivan intègre l'annexion du Texas au déploiement du destin des États-Unis, soit «the fulfillment of our manifest destiny to overspread the continent allotted by Providence for the free development of our yearly multiplying millions. " Pour O'Sullivan, l'ajout du Texas à la fédération américaine ne faisait que confirmer le mouvement général de l'histoire, l'expansion rapide de la population de l'Amérique et son déplacement vers l'Ouest. Dans le contexte d'un mouvement inévitable vers la démocratie, l'annexion des territoires voisins de l'Union devait se faire de plus en plus rapidement. Pour le moment, O'Sullivan rejette l'idée d'une annexion massive du territoire mexicain, mais il anticipe maintenant qu'il y aurait une annexion rapide et complète des territoires «all along our northern borders ", soit l'ajout des colonies britanniques en commençant par le territoire de l'Oregon. Les empires européens étant en déclin, alors que la République américaine connaissait une progression fulgurante, le destin des États-Unis lui semblait assuré. O’Sullivan prévoyait que la population américaine atteindrait deux cents cinquante à trois cents millions en 1945 et que la République dominerait son hémisphère sans que les puissances étrangères puissent s'y opposer ${ }^{33}$.

Les historiens considèrent que cette idéologie jette les bases de l'impérialisme américain, mais les républicains de l'époque voyaient les choses autrement. Pour O’Sullivan, la croissance des États-Unis et l'adoption de son régime républicain par les peuples du Nouveau Monde représentaient une libération plutôt qu'une mise sous tutelle ou la création d'un lien de domination coloniale. Dans un article

32. T. R. Hietala, op. cit., p. 184 ; A. Stephanson, op. cit., p. 39-41 ; B. Loveman, op. cit., p. 59.

33. J. L. O’Sullivan, «Annexation », loc. cit., p. 5-10. 
publié quelques mois plus tard, il expliquait qu'il n'était pas souhaitable de faire une guerre au Mexique pour s'adjoindre son territoire puisque les Mexicains n'étaient pas prêts pour le gouvernement républicain. L'acquisition du territoire mexicain forcerait donc les États-Unis à mettre cette population sous tutelle et à agir comme les empires européens. Évidemment, ce commentaire sur les Mexicains contient un élément de racisme très prononcé, puisque le rédacteur associait la démocratie aux valeurs anglo-saxonnes, mais son discours démontre comment cette idéologie se prêtait à la fois à la critique des empires européens et à la justification de l'accroissement du territoire américain par l'annexion des États voisins. La transformation des années 1840 consistera à insister sur la nécessité de cette expansion pour les États-Unis afin de permettre aux Américains d'atteindre leur destin et de ménager de l'espace pour leur population en pleine croissance ${ }^{34}$.

Malgré un discours dominant qui insistait sur le consentement des peuples qui s'annexaient aux États-Unis, la guerre contre le Mexique (1846-1848) se solde par l'annexion forcée de la moitié du territoire mexicain, soit les États mexicains du Texas, du Nouveau-Mexique et de la Californie. Il n'en demeure pas moins que l'idéologie du Manifest Destiny, avec ses accents providentiels hérités des traditions religieuses américaines remontant au XVII ${ }^{\mathrm{e}}$ siècle, demeure fort influente et elle servira la cause de jeunes nationalistes tels que Stephen Douglas qui feront carrière en insistant sur la nécessité d'occuper le continent américain et d'exploiter les territoires de l'Ouest acquis lors de la guerre contre le Mexique. Le caractère essentiellement raciste de tout cet édifice idéologique et plus particulièrement, l'angle mort que représente l'esclavage deviendra le principal point d'achoppement dans toute cette entreprise et provoquera la Guerre de sécession sur la question de l'esclavage dans les territoires en question.

\section{Le destin républicain et américain d'Amédée Papineau}

Après la bataille de Saint-Charles, Louis-Joseph Papineau quitte le BasCanada et gagne les États-Unis. Son fils Amédée le suivra quelques semaines plus tard et les deux sont réunis à Saratoga Springs en décembre 1837. Papineau sera reçu dans les hautes sphères politiques new-yorkaises et sa famille côtoie celles de l'élite de l'État à Albany et à Saratoga. Sur ce point, la correspondance de Papineau et de son fils ainsi que le journal de ce dernier permettent d'apprécier leur accès auprès des cercles Democrat autour du gouverneur William Marcy. Papineau place son fils Amédée dans la famille du " chancelier " Ruben Hyde Walworth (17881867) qui avait été représentant de son district au Congrès des États-Unis, juge

34. J. L. O'Sullivan, "Territorial Aggrandizement », USDR, XVII, nº 88, octobre 1845, p. 243 248 ; T. R. Hietala, op. cit., p. 177. 
en chef de sa Cour suprême et qui était juge dans la cour de la chancellerie de l'État. Il loge ensuite à Albany chez James Porter, greffier de la cour de la chancellerie de l'État, qui avait été représentant Democrat à l'Assemblée de l'État de New York et au Congrès à Washington. Papineau compte parmi ses connaissances plusieurs figures influentes du Democratic Party new-yorkais, et même un général de l'armée américaine, John Ellis Wool, qui se montre favorable à la cause des Patriotes avant que la politique de neutralité de Van Buren ne soit connue et qui paradoxalement sera l'homme chargé d'arrêter les patriotes de Robert Nelson après leur incursion en terre bascanadienne en février $1838^{35}$. Au cours de l'été de 1838, Papineau et son fils Amédée font aussi un tour des lieux des moments les plus marquants de l'histoire américaine et surtout de la Révolution et de la Guerre d'indépendance. Sur leur voyage de retour, ils rencontrent l'ancien président John Quincy Adams ${ }^{36}$. Pour sa part, Papineau part en tournée diplomatique auprès des membres du Congrès américain afin d'essayer de faire infléchir la politique de neutralité du président américain.

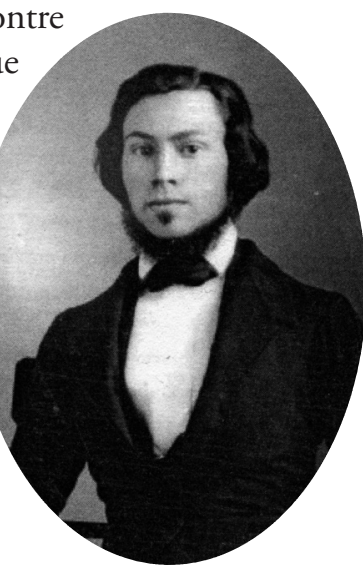

Amédée Papineau (1820-1903). (Source : BAnQ)

De retour à Albany, l'ancien Orateur de l'Assemblée bas-canadienne lit ses journaux aux bureaux de l'Albany Argus, un des principaux organes du Democratic Party new-yorkais ${ }^{37}$. Papineau demeure à New York jusqu'au début de 1839 alors qu'il s'embarque pour Paris et pour un exil plus long en France. Amédée s'installe à Saratoga pour y étudier le droit auprès de Judiah Ellsworth et il devient citoyen des États-Unis en 1842. Admis au Barreau de New York, il y pratique le droit et il épouse l'Américaine Mary Wescott en 1846 avant de rentrer au Canada définitivement ${ }^{38}$. Le journal qu'il tient avec une assiduité variable pendant son parcours américain permet de tracer ses contacts avec les idées d'un républicanisme

35. Louis-Joseph Papineau [LJP] à Amédée Papineau, 28 mars 1838, 2 mai 1838, (de Philadelphie), 28 octobre 1838 (d'Albany) dans Louis-Joseph Papineau, Lettres à ses enfants [LASE], texte établi par Georges Aubin et Renée Blanchet, introduction par Yvan Lamonde, Montréal, Varia, 2004, p. 43-44, 49-51, 58-60 ; « Walworth, Ruben Hyde ", « Porter, John ", "Wool, John Ellis ", dans Who Was Who in America : Historical Volume, 1607-1896. Revised Edition, 1967, p. 632, 490, 688.

36. Amédée Papineau, 9 et 18 juillet 1838, Journal d'un Fils de la liberté [JFL], texte établi par Georges Aubin, Québec, Septentrion, 1998, p. 200-203, 210.

37. LJP à Amédée, 26 octobre 1838, dans L.-J. PaPineau, LASE, op. cit., p. 58.

38. Georges Aubin, "Amédée Papineau : Un Fils de la liberté, 1819-1903 ", dans A. PApineau, JFL, op. cit., p. 11-26. 
continental et d'une destinée manifeste pour les États-Unis. Dès la première année de son exil aux États-Unis, Amédée note dans son journal certains passages tirés de la Democratic Review, et notamment le credo publié dans son premier numéro : "The democratic creed may be summed up in this brief formula : As little governement as possible ${ }^{39}$. Quelques mois plus tard, il note avoir lu les articles de la Democratic Review sur le Canada et aussi un texte plus court sur les exécutions des Patriotes bas-canadiens. Son journal contient plusieurs références à des articles tirés de la revue d'O'Sullivan et à son retour au Bas-Canada en 1845, il cherche à acheter tous les numéros qui contiennent des articles sur les Rébellions. Amédée note également dans son journal des articles sur la démocratie et le destin républicain des États-Unis qu'il aurait utilisés pour la préparation de certains de ses propres textes sur ces questions. Il s'initie aussi aux ouvrages politiques et à la littérature américaine, lisant les auteurs incontournables que sont Thomas Paine et Thomas Jefferson, plusieurs des romans de James Fennimore Cooper et les ouvrages historiques de George Bancroft. Amédée cite également dans son journal la Démocratie en Amérique de Tocqueville ${ }^{40}$.

Ainsi, Amédée Papineau se façonne une culture américaine et il étale sa connaissance de la vie politique de la république dans les lettres qu’il échange avec son père alors en France. Les deux Papineau notent les divisions qui se manifestent au cœur du parti Democrat et la déconfiture du parti new-yorkais suivie par celle de président Van Buren qui perd ses élections devant le Whig William Henry Harrison en 1840. Cette victoire plaît au jeune Amédée, qui ne peut pardonner à Van Buren d'avoir empêché que l'on aide les Patriotes canadiens en 1838. La défaite des Democrats aux élections au Congrès en 1838 lui avait inspiré un commentaire peu élogieux à propos du président : "À bas Van Buren! Il vient de perdre sa majorité aux élections dans son État natal, et perdra encore s'il continue à faire le myrmidon et l'agent de Miss Vic. À bas les ennemis de mon pays, quels qu'ils soient ! ! ${ }^{41}$ "Au moment de l'élection présidentielle de 1840, Amédée prend la parole lors d'une réunion de jeunes électeurs et bien qu'il se garde d'émettre une opinion personnelle puisqu'il n'est pas encore citoyen, il enjoint ses auditeurs de prendre bien soin de réfléchir aux questions telle la politique bancaire ${ }^{42}$.

Il est donc bien établi qu'Amédée Papineau, son père et qu'un certain milieu patriote sont familiers avec la Democratic Review, son contenu républicain et son

39. A. Papineau , Ibid., 10 déc 1838 , p. 265.

40. Ibid., 24 janvier (426) et 25 février (430), 21 mars (435), 31 mars 1841 (436), 29 mars 1842 (488).

41. Ibid., 20 novembre 1838, p. 245.

42. Ibid. 29 octobre 1840 , p. 412. 
discours sur le destin manifeste des États-Unis. Au Bas-Canada, après la résistance et les rébellions, la question de l'avenir de la colonie se pose de façon urgente et elle se pose aussi en termes de destin manifeste, tout en empruntant des lexiques différents. De 1840 à la fin des années 1850, Louis-Joseph Papineau et son fils aîné Amédée, esquissent une première formulation du destin de cette colonie qui paraît dans un cul-de-sac politique. Étienne Parent développe l'idée à sa façon à la fin des années 1840. À la fin des années 1850, un nouveau providentialisme s'annonce dans le lexique d'une "vocation spirituelle ". Le thème s'imposera au moment de la Confédération, tandis qu'Amédée ne démord pas de son utopie jusqu'à la fin du siècle. C'est la dynamique des formes diverses que prend le continentalisme au Bas-Canada après 1840 qui est ici documentée et analysée à la lumière du rôle pionnier que joue la Democratic Review aux États-Unis.

Au tout début de l'Union et avant la courte phase annexionniste de 1849, Papineau, alors en exil à Paris, a connu l'époque des luttes constitutionnelles, de la résistance à la montée de pression britannique, de l'échec de la rébellion de 1838 dont il ne partageait ni les objectifs ni l'initiative, du refus de l'appui du gouvernement américain. Même s'il ne participe pas activement au mouvement d'opposition à l'Union avant sa rentrée d'exil en septembre $1845^{43}$, il commence à concevoir la destinée du Canada dans l'intégration aux États-Unis ${ }^{44}$.

Amédée est toujours aux États-Unis y poursuivant ses études de droit. Il lit les journaux américains, emprunte des livres et assiste à des conférences dans des sociétés culturelles bien pourvues en bibliothèque. Il dispose des moyens pour être à la fine pointe de l'actualité étatsunienne et européenne. C'est à l'occasion de la guerre d'Orient qui oppose l'empire ottoman et l'Angleterre qu'il envisage une émancipation qui ne viendrait plus du continent sur lequel il comptait : "serait-il possible que Dieu voulût nous délivrer de nos oppresseurs, non par l'aide des républicains d'Amérique, mais par celle des Bédouins du désert ${ }^{45}$ ?"

Dès 1842, il est passablement clair pour Amédée que ce qui est désirable, ce qui seul peut faire le Bonheur et la paix permanents des Canadas comme de l'Amérique, ce que j'appelle de tous mes vœux, ce que Le Canadien et d'autres amis

43. Sur les positions politiques de Papineau après 1840, Y. Lamonde et Jonathan Livernois, Papineau Erreur sur la personne, Montréal, Boréal, 2012, p. 93-177.

44. L.-J. Papineau à Amédée, 31 décembre 1841, L.-J. Papineau, LASE, I, p. 137-138; au même, $1^{\text {er }}$ juin 1842 , p. 147.

45. A. Papineau au D ${ }^{r}$ Edmund Bailey O'Callaghan, 3 octobre 1840, Amédée Papineau, Correspondance. Tome I (1831-1841), éditée par Georges Aubin et Renée Blanchet, Montréal, Michel Brûlé, 2009, I, 326. Nous remercions Georges Aubin de nous avoir permis l'accès à la banque de données de la correspondance publiée et à paraître d'Amédée. 
de leur pays semblent redouter, ce qui fait l'horreur des loyalists et du gouvernement anglais, [c'est] l'agglomération de toutes les sections de l'Amérique en une vaste république ; une fédération continentale, une par son esprit et ses lois, une par ses institutions sociales et politiques.

Sur un ton prophétique et évangélique, il ajoute :

Toute l'histoire passée du Nouveau-Monde l'enseigne d'une manière irréfragable. Le doigt de Dieu nous y conduit. Les ennemis comme les amis de l'Humanité, le gouvernement anglais lui-même, travaillent sans cesse et en aveugles à cette œuvre gigantestque. 'Laissez passer la justice de Dieu'46.

C'est dans la lecture de l'ouvrage De la démocratie en Amérique de Tocqueville qu'en 1843 il trouve confortée l'une de ses plus chères idées qu'il dit avoir formulée trois ans plus tôt. Cette idée consiste à penser que le grand avenir des États-Unis sera celui du Nouveau-Monde et bientôt celui de l'humanité :

Je suis fier et réjoui de voir une de mes idées chéries, une de celles que j'estime le plus, que je considère si grande, si féconde pour l'avenir du Nouveau-Monde, de l'humanité entière ; de la voir justifiée et confirmée par une si haute autorité. Il y a près de trois ans, j'écrivais : 'Nous aurons deux vastes confédérations démocratiques, l'une anglaise dans l'Amérique septentrionale, l'autre espagnole dans l'Amérique méridionale'. Et ce soir, je lis dans Tocqueville : ' Il n'y a plus, à vrai dire, que deux races rivales qui se partagent aujourd'hui le Nouveau-Monde, les Espagnols et les Anglais [...]. À une époque que nous pouvons dire prochaine, puisqu’il s'agit ici de la vie des peuples, les Anglo-Américains couvriront seuls tout l'immense espace compris entre les glaces polaires et les tropiques ; ils se répandront des grèves de l'océan Atlantique jusqu'aux rivages de la mer du Sud [...].

Sa géo-politique se fonde sur le crédo démocratique de Tocqueville :

De nos jours, les peuples semblent marcher vers l'unité [...]. L’on pourra voir dans l'Amérique du Nord 150000000 d'hommes égaux entre eux, qui tous appartiendront à la même famille, qui auront le même point de départ, la même civilisation, la même langue, la même religion, les mêmes habitudes, les mêmes mœurs, et à travers lesquels la pensée circulera sous la même forme et se peindra des mêmes couleurs.

À Lamennais qui, avec Thomas Paine et Tocqueville, constitue sa «trinité démocratique ", il emprunte la vision d'une conjugaison de la démocratie et de l'Évangile: "Oh! le glorieux avenir! La démocratie et le christianisme, un et indivisible! L'Âge d'or! Le Millénium ! ${ }^{47}$ " Au moment précis de l'expansion

46. A. Papineau, JFL, 28 février 1842, p. 486.

47. A. Papineau, JFL, 29 octobre 1843, p. 617. 
territoriale des États-Unis, la « marche à l'unité » et son continentalisme comportent manifestement une dimension utopique.

C'est aussi son intérêt pour l'économie politique, domaine relativement nouveau au Bas-Canada de la pensée européenne, qui alimente son utopie. La théorie de la richesse, qui donne à comprendre le développement heureux des sociétés et qui incite les hommes à avancer " avec une croix, une presse, une charte, pour fonder des empires nouveaux, chrétiens, civilisés et libres ", démontre aux hommes " qu'individuellement et collectivement leurs intérêts sont identiques et solidaires. Qu'il n'est qu'une famille humaine, qu'un intérêt, qu'une morale, qu'une justice, qu'une vérité, comme il n'est qu'un Dieu. Et elle nous guide ainsi à marche accélérée dans les voies de la Providence, vers ce centre et ce but de toutes choses, l'Unité Universelle ${ }^{48}$.»

Alors qu'il est revenu d'exil depuis juillet 1843, Amédée n'en continue pas moins de s'intéresser aux États-Unis et à la progression de l'Union vers l'Ouest. Au moment de l'entrée possible dans l'Union de l'Oregon toujours revendiqué par l'Angleterre, il note dans son journal : " Mais ce que j'ai toujours dit et ce qui sera, c'est que les États-Unis auront de l'Oregon tout ce qu'il importe d'avoir, et que, s'ils en laissent à l'Angleterre (pour un temps), ce ne sera qu'un désert inutile. Je dis plus : les Californies seront bientôt annexées à l'Union. Je dis plus : ces colonies anglaises seront annexées dans un avenir plus ou moins prochain ; et de vie d'homme, je crois. Et cela, en dépit d'hommes et diables. Dieu le veut ! Allah ! El Allah ${ }^{49}$ !»

Le grand journaliste Étienne Parent, qui s'était distancé de Papineau et des Patriotes en 1836 et qui est devenu sous-secrétaire du Canada-Uni, tire aussi de sa réflexion sur l'économie politique une sensibilité à la prévision et à la prédiction. Si sa vision paraît moins utopiste que celle d'Amédée Papineau, elle s'appuie davantage sur la providence sans majuscule. Il déclare dans une conférence à l'Institut canadien de Montréal en 1846 :

Ainsi l'a voulu la providence, qui nous a jetés dans ce coin du globe, pour y vivre au milieu de populations étrangères, dont nous ne pouvons attendre beaucoup de sympathie. Ne murmurons pas cependant; car qui peut sonder les secrets de la providence ? qui nous dira qu'elle n'a pas de grands desseins sur nous, et que les

48. A. Papineau, « Notre cercle » [Société des amis], décembre 1844, Revue canadienne, 25 février 1845.

49. A. Papineau, JFL, 8 décembre 1845 , p. 699. 
épreuves auxquelles elle soumet notre adolescence ne préparent pas notre virilité à quelque glorieuse destinée sur ce continent $t^{50}$ ?

L'homme qui pensait depuis un moment que les Canadiens français apportaient à l'Amérique du nord britannique une distinction en Amérique et en assuraient la viabilité persiste à croire que ceux-ci sont porteurs d'un esprit unique : «Nous surtout, Canadiens-Français, issus d'une race éminemment chevaleresque, qui sait si nous ne sommes pas destinés à installer cet esprit de bienveillance et de générosité, sans lequel la société humaine ne saurait atteindre la plus noble de ses fins, le progrès moral et intellectuel de notre espèce ? ». Il invite les jeunes membres de l'Institut à poursuivre leur " œuvre nationale avec constance, et si jamais notre race joue un rôle distingué dans l'histoire de l'Amérique, votre Institut aura droit, j'en suis sûr, d'en réclamer, en grande partie, le mérite et la gloire ${ }^{51}$ ". Un rôle distinctif et distingué pour promouvoir le progrès moral et intellectuel : la vision est à retenir.

Quelques mois plus tard, c'est aussi à l'Institut canadien de Montréal qu'Amédée Papineau développe sa vision de l'avenir de la "Civilisation ». Eu égard à sa conception de l'homme, le républicain qu'il est paraît dominé par l'évangéliste qu'il devient : «Comme dans toutes les grandes révolutions marquées au cachet de la Providence, les hommes sont ici d'aveugles instruments qui travaillent tous à la même œuvre, pendant qu'ils ne croient servir que leurs petits intérêts particuliers. » Millénariste, il déroule la suite de l'histoire : " Les Anglais chassent les Français, les Français chassent les Anglais, les Anglais et les Français chassent les Espagnols ; tous, dans la vue de faire dominer leur empire colonial, le détruisent tour à tour au profit de l'unité continentale! » Tout comme O’Sullivan, le conférencier n'hésite pas à prophétiser et à montrer que l'unité continentale et bientôt « humanitaire » corrigera la confusion linguistique de Babel :

N'en doutons pas, Messieurs, l'Unité Humanitaire a trouvé son berceau en Amérique. Elle y grandira. Cinq cent millions d'hommes-frères occuperont le continent septentrional et parleront un même idiome. Cinq cent millions, le continent méridional, et eux aussi béniront Dieu dans un même idiome. Sur toute l'étendue du Nouveau-Monde, il y aura paix universelle, libre échange universel, fraternité universelle. Et ainsi sera rachetée la malédiction de Babel.

50. Étienne Parent, "Importance de l'étude de l'économie politique », 19 novembre 1846, Discours, édition critique par Claude Couture et Y. Lamonde, Montréal, Presses de l'Université de Montréal, 2000, coll. "Bibliothèque du Nouveau-Monde », p. 128.

51. É. Parent, «Du travail chez l'homme », 23 septembre 1847, ibid. p. 180. 
"Tous les fils d'Adam » parleront l'anglais, mais aussi d'autres langues :

Ce que j'ai voulu dire, Messieurs, c'est donc ceci. Que l'idiome parlé par vingt millions des trente millions qui occupent aujourd'hui l'Amérique du Nord serait la langue universelle de l'unité continentale. Ce qui n'inclut pas de nécessité les langues allemande, française, espagnole et indigènes, que parlent les autres dix millions. Bien loin de là ; il est désirable au contraire de parler autant de langues vivantes que possible; il serait heureux le peuple qui pourrait aller puiser de première main aux trésors intellectuels de l'Angleterre, de la France, de l'Allemagne; et avec l'accroissement de richesses et de bien-être, beaucoup plus rapide encore que celui de la population, que nous promet à tous également l'état social et politique de l'Amérique, nous avons lieu d'espérer des moyens d'instruction et des loisirs pour la plupart des citoyens d'acquérir une connaissance familière et pratique de ces différentes langues.

Le républicain de type américain ajoute Dieu et la Patrie à la devise du républicain français, Liberté, Égalité, Fraternité :

Mais, avant tout, que les fils de l'Anglo-Saxon, du Celte, du Gaulois, du Germain, du Slave, tous fils d'Adam, ne viennent point sur le continent de l'Amérique, cet héritage qui leur est donné à tous en commun et où il y a tant de place pour tout le monde, n'y viennent point s'y entre-haïr et s'y entre-repousser, parce qu'ils prononcent de manières diverses les saints mots de Dieu, Frère, Patrie et Liberté.

À la différence d'O'Sullivan dix ans plus tôt, le conférencier n'a pas eu le temps de montrer « quelle partie de ce grand tout nous appartient, à nous particulièrement, Canadiens ${ }^{52}$. "

\section{Annexion et nationalité colombienne}

Le moment annexionniste (1849-1850) de l'histoire politique du BasCanada rejoint la généalogie de l'idée du continentalisme à deux titres. D'abord, l'annexion est pour certains marchands un choix face à la déception créée par la fin du protectionnisme anglais (Corn laws, 1846) et un choix plus ou moins positif fait par quelques Canadiens français conscients, durant les premières années de l'Union, d'avoir épuisé toutes les solutions possibles : luttes constitutionnelles, résistance, rébellions, opposition vaine à l'Union. Au Bas-Canada, pour les tenants républicains convaincus mais rares de l'annexion, celle-ci est le point de départ d'une adhésion soutenue à une vision de l'intégration du Bas-Canada dans une

52. A. Papineau, "Civilisation ", avril 1848, Bibliothèque et Archives nationales du Québec [BANQ], Centre de Québec, P417/10.3.1.7.1 ; «Lecture de M. Amédée Papineau » La Minerve, $1^{\text {er }}$ mai 1848 . 
géopolitique continentale. Papineau et Amédée ne signent pas le manifeste annexionniste de décembre 1849, mais le premier appuie l'initiative dans une lettre à L'avenir ${ }^{53}$. Amédée se présente comme « annexionniste et américain continental " (lettre du 13.11.53), persiste et signe à propos d'un éventuel système de protection de l'Amérique continentale (22.2.52) ou du "triomphe de la démocratie européenne et [de] la république universelle " (2.10.53) au moment où, à nouveau, la question d'Orient se repose et où la guerre de Crimée éclate. Dans son style d'observateur-prophète, Amédée décrit la situation européenne à son père :

L'Autriche et la Prusse se rangent avec le Russe. La France même, ou plutôt son tyran, trahit la Turquie. L'Angleterre reste seule, isolée. Les Cosaques triomphent, nouveaux débordements des barbares. Ils dévorent l'Empire ottoman. Ils en jettent le lambeau, de l'Adriatique à l'Autriche, le lambeau égyptien à Napoléon le Petit. L'Angleterre, asile de tous les rebelles et les brigands, est mise hors la loi. On coupe son Empire en deux, on en sépare complètement les deux tronçons. Il lui faut une lutte à mort pour les rapprocher et les relier. Elle fait appel à tous les révolutionnaires. La grande bataille arrive entre la démocratie universelle et la civilisation, d'une part ; le despotisme et la barbarie, de l'autre! Quel siècle! Quelle épopée $e^{54}$ !

Vingt ans après le grand discours de Emerson, "The American Scholar " (1837), Amédée sent bien le rapport qui existe entre l'existence d'une épopée et le récit impératif de cette épopée. Face à ces États-Unis qui ont « la grande épopée de leur colonisation et de leur révolution à écrire, la démocratie moderne à fonder, et leur République continentale à gouverner », il se demande : «les États-Unis ont-ils une littérature ? "Sa réponse à la question suggère que le cas étatsunien est « notre enseignement » :

Elle naît à peine, et l'on peut leur compter une vingtaine d'hommes de lettres distingués, dont les œuvres passeront peut-être à la postérité. Encore, combien de ces œuvres portent le cachet de l'originalité et ne sont pas des copies anglaises ? Avant Cooper et Washington Irving, l'on cherche en vain le type d'une littérature américaine et nationale. Ce type est encore vague et mal défini : la nation est encore trop jeune pour le posséder et pour le refléter dans ses écrits. Mais la nation qui est trop jeune encore pour avoir une littérature nationale et classique, a eu Franklin,

53. La liste des signataires du manifeste se trouve dans Thomas Chapais, Cours d'histoire du Canada, Québec, librairie Garneau, 1933, tome VI, p. 307-345 ; L.-J. Papineau, «À Messieurs les membres du comité annexionniste ", 25 octobre 1849, L'avenir, 3 novembre 1849 , repris dans L.-J. Papineau, Un demi-siècle de combats. Interventions publiques, choix de textes et présentation par Y. Lamonde et Claude Larin, Montréal, Fides, 1998, p. 563-568.

54. A. Papineau à L.-J. Papineau, 9 octobre 1853, BAnQ-Q, P417/3,2.1.5 et BAnQ-M, P7/1, 5/9-27. 
Washington, Jefferson, Fulton, Whitney, Kent et Livingston, Dewitt Clinton, Silliman, Audubon, Morse, Beecher ; ses physiciens, naturalistes, ingénieurs, mécaniciens, inventeurs, légistes et hommes d'état. Avant la victoire intellectuelle, il faut la lutte et la conquête matérielle. Il faut asseoir la société sur les bases solides d'une prospérité réelle et permanente, avant qu'elle puisse se livrer sans entraves et sans d'inquiètes distractions aux douces jouissances de la culture des arts et des lettres ${ }^{55}$.

C'est à compter de 1854 que Papineau père, avec un bagage politique différent et sur un ton moins prophétique, commence à formuler sa conception continentale du Bas-Canada. Favorable à l'annexion plutôt qu'à tout scenario de moins en moins probable d'indépendance du Canada vis-à-vis de l'Angleterre, assumant l'assimilation qui s'en suivrait, Papineau entrevoit que le Bas-Canada deviendra un État, non pas un État souverain, mais un des États des États-Unis. Sa conception du statut de l'État dans l'Union américaine semble satisfaire ses attentes républicaines et nationales dans la conjoncture des contraintes contemporaines du destin possible du Bas-Canada. À une nationalité nouvelle, "néocanadienne et mixte ", il préfère une nationalité tout aussi mixte mais américaine. Il voit même cet État du Québec - State of Quebec, vraisemblablement - faire partie d'un tout continental, d'une "nationalité colombienne ${ }^{56}$ ", allusion à l'Amérique de Christophe Colomb. Dans cette décennie de 1850 qui révèle à la fois l'évolution démographique du Canada-Uni et les limites du régime d'Union de 1840, Papineau demeure annexionniste et voit les avantages de :

l'annexion le plus tôt possible et de l'association à ce qui sera demain le plus noble théâtre intellectuel et le plus heureux état politique qu'il y ait au monde, au lieu de l'état colonial ? L'Angleterre veut organiser ses faibles colonies pour un prochain état d'indépendance qui les enlacerait dans un système d'alliance avec elle, qui les rendra complices de ses querelles futures, auxquelles son système d'exploitation commerciale l'entraîne plus fréquemment qu'aucune autre des nations de l'Europe.

Si elle se présente comme moins prophétique, cette vision comporte une analyse que l'avenir ne démentira pas. Papineau qui avait 37 ans au moment de la formulation de la doctrine Monroe (1823) a développé une conscience historique qui lui fait lire le passé, le présent et le futur d'une façon originale. Il a ainsi expliqué le sens de la doctrine Monroe au représentant-imprésario de Lamartine en Amérique, Jean-Baptiste Desplace :

55. A. PAPINEAU, «Essai sur la littérature canadienne » fait devant l'Institut canadien de Montréal, 17 décembre 1853, BAnQ-M, P28, S4, D1. O'Sullivan avait publié dans la USDR du mois d'août 1842 un article sur le sujet, "Democracy and Literature». Il y plaidait pour une littérature qui exprimerait les valeurs démocratiques de la république.

56. L.-J. Papineau à Amédée, 31 décembre 1854, L.-J. Papineau, LASE, I, p. 639. 
Je l'engage à continuer avec eux la discussion commencée avec moi pour la doctrine Monroe, méridien des Açores, point de partage entre les systèmes européens et américains. Vingt royaumes mangés par des armées permanentes; et trois républiques, l'américaine par excellence, soleil qui éclaire et échauffe et instruira les Amériques espagnoles et portugaises, toutes trois sans armées ni flottes, ni Églises liées à la politique de l'État ; intronisant une ère nouvelle et meilleure dans la constitution sociale de l'humanité. La politique québécoise, lui ai-je dit, est soufflée par l'Angleterre qui voudrait introduire ses propres institutions avec son alliance en Amérique. Je lui ai donné à réfléchir ${ }^{57}$.

Au moment où une autre conception de la continentalité du Bas-Canada est sur le point d'être formulée, Amédée fait à ses père et mère, en janvier 1859, un aveu qui donne l'heure juste sur le destin de sa propre conception du destin du Bas-Canada telle qu'il l'avait formulée en 1848 :

L'Institut [canadien] me demande une lecture. Ne serait-ce pas folie d'ajouter un faux ton de plus à toute cette cacophonie ? Je ne veux pas avoir l'outrecuidance de prétendre démêler ce nœud gordien. Je l'ai essayé un jour, et le prophète ne fut pas compris. Au bout de dix années pourtant, il s'est découvert un disciple. Joseph Doutre, qui lapidait le prophète lorsqu'il prêchait. Et pourquoi irais-je crier les mêmes vagueries qui me sont restées au cœur et au cerveau ? Pour recevoir de nouvelles pierres de la nouvelle génération de l'Institut ? J'aime mieux laisser toute la besogne à la Providence. Je rêve toujours qu'elle pense à nous, vermisseaux, et qu'elle nous fusionne pour l'unité continentale, humanitaire et républicaine. Fiat Voluntas Dei ${ }^{58}$.

\section{Une vision continentale catholique}

L'usage plus ou moins indifférentié du mot " providence » (sans majuscule) est fréquent dans le vocabulaire de l'époque. La notion même de providentialisme était au cœur de la conception de la monarchie absolue : il y avait représentation de l'autorité de Dieu dans l'autorité du Roi, sans compter que " la main de Dieu » pouvait être agissante selon les besoins. Vers 1790, le juge Smith avait formulé l'idée que c'était la Providence qui avait évité aux catholiques "canadiens " les horreurs de la Révolution française en permettant la conquête de la colonie par les Anglais.

C'est Étienne Parent qui, dans l'histoire plus récente du Bas-Canada, avait mis en circulation l'idée d'une vocation spécifique possible pour les Canadiens français. Double vocation : celle de contribuer au maintien de l'Amérique du

57. L.-J. à J.-B. Desplace, 29 décembre 1856, L.-J. Papineau, LASE, II, p. 201.

58. A. Papineau à son père et sa mère, 15 janvier 1859, BAnQ-M, P7/1, 6/10-68. 
nord britannique en la distinguant de la majorité anglophone et protestante des États-Unis, puis celle d'identifier la majorité francophone bas-canadienne à son appartenance à une " race éminemment chevalesresque » et porteuse « d'un esprit de bienveillance et de générosité ".

Le messianisme catholique en Amérique s'énonce dans un contexte de redécouverte de la France au moment (1855) où un navire français, La Capricieuse, remonte le Saint-Laurent pour la première fois depuis la Conquête. Le contexte est aussi celui du progrès économique et matériel des États-Unis " protestants " et, faut-il le rappeler, de la fin de la crise annexionniste de 1849 et de 1850 . Il importe de saisir que la vocation catholique du Canada français en Amérique qui s'énonce alors et qui va prévaloir pendant quasi un siècle, trouve son sens dans la volonté de ne plus voir se reproduire un projet annexionniste manifestement néfaste pour la religion et, secondairement, pour la langue française. Enfin, ce messianisme religieux s'appuie doctrinalement sur l'ultramontanisme en essor qui veut que, dans une hiérarchie des fins, la religion prévale sur le civil dans des domaines où la croyance et la morale seraient en jeu.

En 1856, Pierre-Joseph-Olivier Chauveau rappelle l'assurance du destin de Dieu et de la religion par la France ("Gesta Dei per Francos») tandis que le sulpicien Rouxel développe l'idée de la vocation religieuse de la colonisation de Montréal ${ }^{59}$.

L'homme qui vient consacrer cette vision est un Français, Edme Rameau de Saint-Père (1820-1899) qui, après une évolution politique qui le mène de Proudhon à Le Play, s'intéresse au phénomène de la colonisation, en particulier à celle de l'Algérie que la France de Louis-Philippe vient de conquérir et dont elle amorce le développement. Ce serait au début des années 1840 que Rameau de Saint-Père ayant entendu parler du Bas-Canada et des Français qui y habitent, aurait pensé la réussite de la colonisation de l'Algérie en contraste avec l'échec que la France avait connu en Amérique. Il cherche à s'expliquer le triomphe du style britannique de colonisation en regard des insuccès de celui de

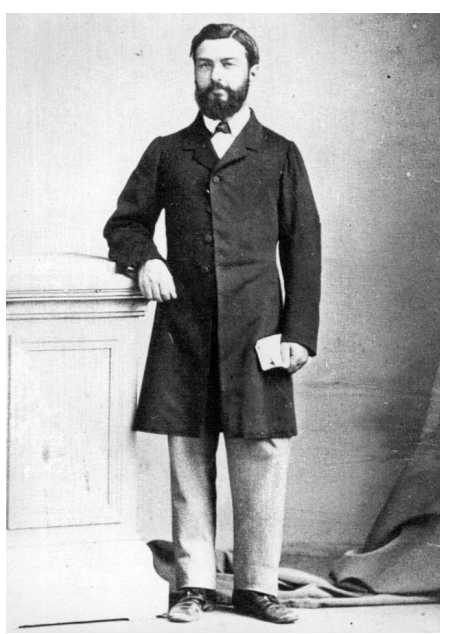

François-Edme Rameau de Saint-Père (1820-1899), historien et sociologue français. (Coll. privée)

59. Sur cette question, Y. LAmonde, Histoire sociale des idées au Québec. I : 1760-1896, Montréal, Fides, 2000, p. 384-395. 


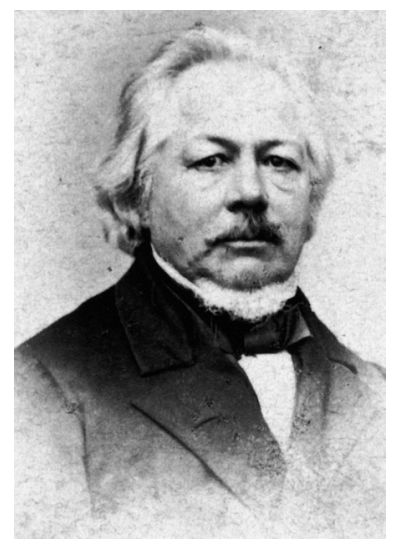

Étienne Parent (1802-1874) homme politique, journaliste et fonctionnaire. (Source : Bibliothèque del'Assemblée nationale)

la France. Pour lui, cet échec fut celui de la France et non des Français qui s'y étaient établis ${ }^{60}$.

Tenant de l'idée que la situation des Canadiens et des Acadiens se rattachait à l'état social de la vieille Europe, il publie en 1859, cent ans après la Conquête, La France aux colonies qui marquera l'évolution intellectuelle du Canada français. Il est difficile d'évaluer ce que Rameau de Saint-Père doit à Étienne Parent, qui avait développé depuis dix ans l'idée d'un possible destin providentiel du Bas-Canada. La correspondance connue de Rameau commence en 1858 et la première lettre de Parent à son correspondant français date de 1861, année où celui-là effectue son premier voyage au Canada. Parent y affirme que le Bas-Canada est la France en Amérique ${ }^{61}$.

Dans un chapitre au titre explicite, «De l'avenir moral et intellectuel des Canadiens en Amérique ", le disciple de Le Play met en valeur l'importance dans les sociétés des facteurs moraux et intellectuels. Il prescrit pour le Canada français un embargo « sur ce qui sent l'américanisme », la " civilisation malsaine ", "le veau d'or ». Il écrit : "Il nous semble point être dans la destinée du Canada d'être une nation industrielle ou commerciale " tout en proposant pour lui « le culte du sentiment, de la pensée et du beau ». Chez ce "peuple choisi ", le soutien de la nationalité est associé à celui de la religion $^{62}$.

Davantage que ses contemporains catholiques, c'est l'abbé Henri-Raymond Casgrain qui vient consacrer l'idée et la formule en 1866 :

Quelle action la Providence nous réserve-t-elle en Amérique? Quel rôle nous appelle-t-elle à y exercer ? Représentant de la race latine, en face de l'élément anglosaxon, dont l'expansion excessive, l'influence anormale doivent être balancées, de

60. Pierre et Lise Trépanier, « Rameau de Saint-Père et l'histoire de la colonisation en Amérique ", Acadiensis, IX, no 2, printemps 1980, p. 40-55.

61. E. Parent à Rameau de Saint-Père, 25 octobre 1861, cité dans : JeAn Bruchesi, «Les correspondants canadiens de Rameau de Saint-Père ", Les Cahiers des Dix, 14 (1949), p. 87-114, citation p. 105. http://www.nosracines.ca/f/page.aspx?id=369759

J. Bruchesi exploite ici le fonds Rameau de Saint-Père (P223, Microfilm 53) à Bibliothèque et Archives nationales du Québec.

62. François-Edme Rameau de Saint-Père, La France aux colonies, Paris, Jouby, 1859, p. 250269. 
même qu'en Europe, pour le progrès de la civilisation, notre mission de même de que celle des sociétés de même origine que nous, éparses sur ce continent, est d'y mettre un contrepoids en réunissant nos forces, d'opposer au positivisme angloaméricain, à ses instincts matérialistes, à son égoïsme grossier, les tendances plus élevées, qui sont l'apanage des races latines, une supériorité incontestée dans l'ordre moral et dans le domaine de la pensée.

Le programme deviendra « la vocation catholique de la race française en Amérique $^{63} »$.

\section{Le destin de l'idée du destin du Canada français : Papineau (père et fils) et Parent}

La guerre civile aux États-Unis remet en cause la vision « colombienne » de Papineau, car les États-Unis se mettent à ressembler à l'Europe :

Alea jacta est. La vision de Colomb est évanouie. L'Amérique est entraînée dans le système européen d'équilibre, de changement perpétuel d'alliances, de guerres incessantes, d'armée permanente, de tout ce qui est mal là-bas d'abord. Ce qui y est bien et mieux qu'en Amérique, le culte des lettres, des sciences et des arts, l'élégance des manières et l'esprit de sociabilité, ne s'y généralisera que dans un avenir éloigné. La dissémination des populations dans d'interminables forêts et prairies y empêchant les frottements qui polissent. Je mourrai dans le deuil et contristé, plus que je ne l'avais prévu.

Papineau réitère son credo colombien à l'Institut canadien de Montréal le 17 décembre 1867 , le jour du $23^{\text {e }}$ anniversaire de l'association. Il y aborde la question « colombienne » de manière plus philosophique; selon lui, il est toujours de l'intérêt des "établissements nouveaux en Amérique " de "demander leur émancipation le plus tôt possible, et d'acquérir tous les avantages et tous les privilèges de nationalités nouvelles, tout-à-fait indépendantes de l'Europe ». Il qualifie " d'aveugles » ceux « qui parlent de la création d'une nationalité nouvelle, forte et harmonieuse, sur la rive nord du Saint-Laurent et des grands lacs », d'une nationalité qui serait " déjà toute formée » et " confinée dans ses limites actuelles ". Cette nationalité sera aussi marquée par l'immigration, comme toutes les nations américaines et elle sera composée « de toutes les races d'hommes qui, avec leurs mille croyances religieuses, grand pêle-mêle d'erreurs et de vérités, sont poussées par la Providence à ce commun rendez-vous pour fondre en unité et fraternité toute la famille humaine ». Ce « fait » est pour lui « trop évident sur toute l'éten-

63. H.-R. CASGRAin, «Le mouvement littéraire au Canada » (1866), Euvres complètes, Montréal, Beauchemin, 1896, tome I, p. 370 et 373. 
due de l'Amérique et dans toute son histoire, depuis sa découverte par Colomb ". C'est sur « cette base solide » que « l'homme du Nouveau-Monde » doit « asseoir la société nouvelle et ses nouvelles institutions ". Papineau laisse son auditoire sur ces paroles : « La patrie n'aura de force, de grandeur, de prospérité, de paix sérieuse et permanente, qu'autant que toutes ces divergences d'origines ou de croyances s'harmoniseront et concourront ensemble et simultanément au développement de toutes les forces et de toutes les ressources sociales ${ }^{64}$."

Papineau reviendra une dernière fois sur le sujet, un an avant sa mort. $\grave{A}$ Amédée qui voyage avec sa famille en Europe en 1870, il propose d'aller convaincre des hommes publics anglais de sa vision colombienne septentrionale, des intérêts mêmes de l'Angleterre à acquiescer à cette nouvelle géopolitique ; il invite son fils à participer à la préparation de ce "concile œecumémique rationnel» :

Il sera repris plus tard par quelques-uns de vous, non par tous. Il sera intéressant d'avoir vu les populations dans les divers états, antérieurs et postérieurs à la guerre [franco-prussienne]. Elle va produire des altérations profondes et générales. Les deux géants qui se ruent l'un contre l'autre ne peuvent s'épuiser dans une courte lutte. Elle est longue. Elle deviendra générale pour l'Europe, et la paix constante pour l'Amérique où, avant la paix européenne, les États-Unis auront atteint leur but providentiel : une confédération unique de tout le continent septentrional. Viens prendre ta part au concile œcuménique rationnel, et non visionnaire, qui arrangera les destinées de notre patrie. Il y a en ce moment l'occasion de lui rendre les plus grands services possibles, soit à Washington, soit à Londres. Avant de revenir ici, vois M. Motley et, par lui, MM. Bright et Gladstone, et représenteleur fermement tous les motifs de sage politique et de sainte philanthropie qu'ils ont d'adopter la combinaison politique la plus propre à éloigner pour un long avenir les dangers de la guerre étrangère pour tout un continent. Et ce continent ne sera-t-il pas d'autant plus utile à l'Europe, comme refuge de colonisation, que la paix, la prospérité, l'accroissement, la richesse s'y développeront plus rapidement.

Le schéma de Papineau a quelque peu évolué en se précisant ; conséquent avec son argument de l'importance de la taille des territoires gouvernables, il écrit :

Mais, pour que toutes les parties du continent soient aussi homogènes que possible, il faut qu'il n'y ait pas qu'un État du Bas-Canada avec un territoire double de celui de New York, un seul État [du] Haut- Canada avec un territoire double de celui de la Pennsylvanie. Le Bas-Canada devra former trois États, et le Haut, deux, pour

64. Louis-Joseph Papineau, Un demi-siècle de combats. Interventions publiques, p. 606, 610-611. 
prévenir toute idée de retour vers la forme monarchique. Parce que nous avons trois ou quatre baronnets anglais, ce germe de mauvaise institution plait à quelques hommes faibles et vains et à tout le clergé, qui aime partout la concentration du pouvoir, quand nous en aimons la diffusion. C'est par le cabinet anglais que cette combinaison doit être appuyée. Elle ne peut être suggérée par nos hommes du gouvernement. Elle ne peut l'être que par l'opposition.

Il lance donc cet impératif à Amédée : "Age! [Agis !] Demeure à Londres ${ }^{65}$. " Il estime que ce scenario aurait l'aval des États du Nord : " au jour de l'annexion, vu l'étendue de territoire des Canada, ils [le Bas et le Haut-Canada] devraient constituer 5 à 6 États dans la confédération. Cette idée doit être la considération principale dans tout plan de future combinaison politique. Tous les États du Nord au Congrès le favoriseront ${ }^{66} \%$.

À l'occasion de la fête du patron du Canada français et dix ans après l'ouvrage de Rameau de Saint-Père, Parent, alors sous-secrétaire du Canada à Ottawa, donne des exemples d'événements providentiels qui ont marqué le Canada français. Un an après l'établissement de la Confédération canadienne, il déclare : "Je ne crains pas de le proclamer, Messieurs, la Confédération du Canada, à mon avis, est un de ces événements providentiels, dont notre histoire offre plusieurs exemples ». Parmi "d'autres événements providentiels en notre faveur ", il reprend l'idée de la Conquête providentielle par l'Angleterre : "On est forcé de s'avouer aujourd'hui que si la tourmente révolutionnaire en France nous eût trouvés encore sujets français, nous en eussions rudement ressenti le contrecoup ; tandis que, sous la protection du drapeau britannique, nos pères purent réparer tranquillement la ruine où les avait laissés, je ne dirai pas la France, qui était aussi malheureuse que le Canada, mais le gouvernement corrompu de l'amant de la Pompadour ». Inspiré par l'Histoire Sainte et le destin des Juifs, il affirme : " Mais il faut excuser nos pères de n'avoir pas, en cette occasion, su pénétrer les desseins de la Providence, qui préparait leur salut national et le nôtre, tandis que, sur les bords du Saint-Laurent, ils pleuraient au souvenir de la France, comme autrefois les Juifs, sur les bords des fleuves babyloniens, au souvenir de Sion ». Dernier exemple, récent : "N'est-ce pas aussi un coup de la Providence que cette victoire de Châteauguay où notre Léonidas canadien ", le colonel de Salaberry a sauvé le Bas-Canada?

Parent se réjouit de la sollicitude de la Providence : "Heureux et grands devant Dieu et devant les hommes sont ceux que la Providence choisit pour produire les grandes œuvres comme celle qui nous occupe ». Les Canadiens

65. L.-J. Papineau à Amédée, 21 juillet 1870, L.-J. Papineau, LASE, II, p. 622.

66. Ibid., 8 septembre 1870 , p. 638. 
français n'ont-ils pas été « de la part de la Providence, l'objet d'une protection toute particulière? " : Que même dans nos temps d'épreuve et de malheur, elle nous préparait à remplir dignement le rôle qu'elle nous destinait sur la terre d'Amérique ? Ce rôle ou plutôt cette mission, c'est évidemment de fonder et propager la civilisation franco-catholique sur ce continent. Et cette œuvre n'estelle pas déjà commencée ? " Cette œuvre est celle des prêtres missionnaires catholiques : "Malgré nos faibles ressources, n’avons-nous pas pu envoyer déjà de courageux apôtres de l'Évangile jusqu'aux régions glacées du Nord et de saintes religieuses jusque sous les feux des tropiques? " L'émigration aux États-Unis lui semble une autre forme de mission : "Puis on calcule qu'il y a maintenant aux États-Unis deux cent mille de nos compatriotes qui, lorsqu'ils se trouvent réunis sur un point en nombre suffisant y forment presque partout une société SaintJean-Baptiste $[\ldots] »$.

Si les Canadiens français évitent la division, ils seront les soldats de Dieu :

Qui donc nous empêchera d'accomplir notre mission ? Une seule chose, Messieurs, l'esprit de discorde qui engendre trop souvent l'esprit de parti dans un pays libre. Soyons donc unis, si nous voulons qu'on dise de nous pour l'Amérique ce qu'on a dit de nos pères de la vieille France pour l'ancien monde : gesta Dei per francos. Encore une fois soyons unis et nous mériterons aussi le plus bel éloge que l'on puisse faire d'un peuple : gesta Dei per Canadenses ${ }^{67}$.

Ces visions se fondent sur une nationalité culturelle de conservation sans projet d'émancipation politique sous la forme d'un État souverain ou d'un État de l'Union américaine.

\section{Amédée Papineau : irréductible continentaliste}

Alors que la "vocation de la race française ", d'abord catholique, en Amérique se consolide - on en fera le Bréviaire du Canada français en 1925 et $M^{\mathrm{gr}}$ Louis-Adolphe Pâquet en sera l'oracle -, Amédée persiste et signe jusqu'en 1900. Il voit venir "la République continentale et la démocratie purifiée de l'esclavage ${ }^{68}$ " et s'agiter en Europe " le Bien et le Mal, le Peuple et les Tyrans, Démocratie et Despotisme " alors que la Grande Révolution américaine " entraîne l'Humanité dans la voie du progrès vers la Fraternité et la Liberté

67. É. Parent, «La Confédération », dans Discours, op.cit., p. 446, 447, 449, 450.

68. A. Papineau à ses parents, 10 novembre 1861, Bibliothèque et Archives Canada, MG24, B2, vol. 39, dossier 4 ou Microfilm C-15799. 
universelles ${ }^{69}$ ". À son père déçu de la guerre civile aux États-Unis, il fait valoir la ténacité de ce peuple :

Ce peuple est capable de passion ou d'enthousiasme, mais il a cette foi et cette ténacité de résolution qu'il hérite de sa race anglo-saxonne. Ce n'est pas beau et pittoresque et théâtral, comme à Paris ou à Milan, mais c'est inexorable comme le Destin, comme la force créatrice. Ça ne passe pas en fumée pyrotechnique, comme une démocratie parisienne, mais ça rassure sur le sort inévitable de la démocratie et de l'Unité continentale ${ }^{70}$.

En 1870, Amédée retourne devant les membres de l'Institut canadien de Montréal, sur le point de disparaître, et choisit son lexique :

Je vous présente la Vierge de la Liberté. Qu'elle préside à toutes nos réunions, à nos délibérations, à nos études. D'une main puissante elle broie les tronçons des emblèmes d'esclavage, des tyrannies et des superstitions, qu'elle a renversés; et elle est prête à les rejeter avec dédain. L'autre main, appuyée sur la Bible, épitomé chez les chrétiens de la vérité morale et religieuse, présente aux peuples émancipés la branche d'olivier, emblème de la paix et de la fraternité universelle.

La Vierge de la Liberté est aussi celle de l'Égalité :

La couronne et sa gloire, c'est le bonnet de l'égalité. Égalité qui est l'apanage de toutes les têtes humaines. Dans les degrés d'intelligence et de fortune, les variations sont infinies. Mais tout homme a un droit égal à atteindre par le travail et la vertu, la première place dans l'estime de ses concitoyens et les plus hautes fonctions dans l'administration de son pays ${ }^{71}$.

La situation du Mexique lui suggère des comparaisons; un extrait d'une lettre à son épouse Marie Westcott, reprise de son " Journal », explique en 1884 :

I am reading about Mexico which is becoming accessible by railroads, that the Yankees are building to cross it in various directions. Preliminaries, I suppose, to its annexation. It is more desirable certainly than the snow fields of our Canadian Dominion. We may be yet left long in the cold, and Mexico enjoy first the blessing of that continental Unity which is the certain Destiny of North America. It was the dream of my life to see it. But I fear this fleeting hour of one human generation is too short for my enjoyment of that day, that glorious day ${ }^{72}$.

69. Le même aux mêmes, 16 mars 1862, BAnQ-M, P28/S3/D5.

70. A. Papineau à L.-J. Papineau, 17 juillet 1863, BAnQ-M, P28/S3, D5.

71. A. Papineau, "Adieux à l'Institut canadien », conférence à l'Institut canadien de Montréal, 24 avril 1870, BAnQ-Q, P417/10, 3.1.7.1.

72. A. Papineau, "Journal ", 1884, BAnQ-Q, P417/8 ; une entrée du "Journal " ( $1^{\text {er }}$ janvier 1893) réfère à un poète américain, Joaquin Miller, connu comme "le poète des Sierras", qui prophétisait que "la feuille d'érable et le cactus de Darien » figureraient bientôt sur "l'écusson de la grande République continentale». 
Amédée est constant dans sa lecture des événements européens toujours susceptibles de faire avancer la cause continentale :

Quand et comment sortirons-nous [de ce cloaque de servilisme] est un problème difficile à prévoir ; vous et moi ne le verrons pas, mais l'histoire nous éclaire : il est certain que notre malheureuse patrie sortira de l'esclavage pour monter au sort commun à toutes les contrées des Amériques, l'Indépendance absolue des pouvoirs européens. Elle n'est pas comme la pauvre Érin, sous le talon du despote : elle en est trop éloignée ; sa chaîne est trop longue pour qu'elle ne se rompe pas un jour comme de son propre poids. Le Canada, seul comme le Mexique, ou plus probablement comme le Mexique dans la Constellation continentale, jouira pleinement de la Liberté et de la nationalité, pendant que l'Angleterre resserrée de plus en plus dans son îlot, verra grandir et l'éclipser l'Allemagne, la Russie et surtout les États-Unis d'Amérique, la plus grande puissance qu'aura jamais vue l'Humanité ${ }^{73}$.

S'il voit naître une « confédération prochaine des États-Unis d'Europe » qui " déduisent que la destinée manifeste, inévitable, providentielle de toute l'Amérique du Nord est de ne former qu'une seule République Continentale du pôle arctique à l'isthme de Panama ${ }^{74}$ ", la consolidation de l'empire britannique ne lui échappe pas. Si l'émancipation toujours éventuelle du Canada lui semble acquise, il ne faut pas contribuer pour autant à cet empire :

$[\mathrm{M}]$ ais aujourd'hui que nous voyons percer les projets gigantesques de la métropole, de fortifier ces colonies, d'y créer des écoles militaires et des armées, d'y construire des chemins de fer, des câbles télégraphiques, des lignes de steamers, pour relier ses colonies d'Amérique avec celles d'Australie, et finalement de se les incorporer toutes comme parties intégrales de l'Empire britannique, et que tous les partis au Canada s'entendent pour repousser l'idée de s'annexer jamais à nous, nous ouvrons enfin les yeux, et nous voyons que c'est en Amérique et comme chez nous-mêmes que l'Angleterre veut établir sa rivalité militaire autant que commerciale. Holà, nous ne saurions y aider et contribuer!

Pour ce faire, il souhaite la création d'une «Ligue Nationale et Patriotique en opposition à la Ligue Fédérative Britannique ${ }^{75}$ ».

Il est frappant de voir comment Amédée pense et prophétise les choses en dehors de tout rapport de force ; il suffirait de demander :

Avant que les difficultés deviennent plus sérieuses, et les complications plus difficiles à résoudre ; avant que les esprits s'aigrissent et que l'honneur des deux nations

73. A. Papineau à Joseph-Guillaume Barthe, 20 avril 1885, BAnQ-Q, P417/8,3.1.4.

74. "Un Patriote [A. Papineau], La Patrie, 19 décembre 1888, BAnQ-Q, P417/8,3.1.5.

75. A. Papineau à Ernest Pacaud, 24 janvier 1889, BAnQ-Q, P417/8,3.1.4. 
ne soit en jeu, il me semble que ce serait pour nous, Canadiens, de demander notre émancipation à la mère patrie ; ce serait pour elle de nous donner, avec sa bénédiction, notre entière Indépendance et de nous reconnaitre et admettre au nombre des nations libres et souveraines. Alors nous pourrions négocier avec les États-Unis et régler nos rapports avec eux, dans nos intérêts mutuels et sans blesser les susceptibilités de personne.

Il a ensuite un scénario pour le destin du Canada auquel l'Angleterre aurait accordé l'indépendance :

L'ambition générale des Canadiens pour une nationalité à eux, propre, que professent les conservateurs comme les libéraux, se trouverait pleinement satisfaite. Les annexionnistes remettraient à un avenir éloigné et peut-être problématique, la fusion dans la République Continentale. Les protectionnistes auraient le tarif américain encore plus élevé que le nôtre. Les libre-échangistes auraient le marché de 70 millions pour favoriser leurs prédilections. Les Anglais parmi nous qui sont plus attachés à leur Home d'outremer qu'à leur pays d'adoption, se soumettraient loyalement à la décision de leur mère patrie par dévouement à sa volonté et pour lui épargner une guerre désastreuse avec les États-Unis. L'Angleterre elle-même trouverait dorénavant dans les Américains ses meilleurs amis et alliés, comme ils sont ses meilleurs chalands, au lieu d'antipathies et d'achoppements continuels ${ }^{76}$.

Amédée n'a de cesse de prophétiser et de prêcher, y compris à l'adresse de son neveu, l'abbé Gustave Bourassa. À nouveau, il enrobe sa conviction du vocabulaire approprié :

Pour me comprendre, mon cher et bien-aimé neveu, il faut te rappeler ma lettre, pendant que tu faisais tes études théologiques à Rome. Les sentiments de tolérance, d'éclectisme, de fraternité universelle, qui m’animaient alors, ne peuvent se déraciner de mon cour, ni de ma conscience. Comment le pourraient-ils jamais ? J'y suis confirmé par l'admirable, on pourrait dire presque miraculeux et providentiel, concours que l'Amérique libre pouvait seule concevoir et réaliser, 'le Parlement des Religions'. Ce concile œcuménique de tous les enfants de l'Éternel Père céleste, de tous les Frères de l'Humanité entière, réunis à Chicago pendant l'Exposition colombienne ${ }^{77}$.

76. A. Papineau à La Justice, 19 novembre 1888, BAnQ-Q, P417/8,3.1.5.

77. A. Papineau à G. Bourassa, 14 octobre 1894, BAnQ-Q, P417/8,3.1.4. 


\section{Retour sur l'idée continentale}

Au Québec, le continentalisme naît d'abord dans un providentialisme vaguement religieux - l'appel à la Providence - renforcé d'un providentialisme politique où le conquérant présente sa propre conquête coloniale comme une planche de salut à l'égard de l'horreur révolutionnaire de 1789. Amédée Papineau qui, sur cette question, oriente la pensée de son père, y ajoute une dimension utopiste faite d'adamisme - tous les fils d'Adam - et d'un millénarisme achevé dans l'Unité Humanitaire. On retrouve chez le fils un très fort accent d'utopisme que le père atténue sans le réduire complètement ; les responsabilités et l'expérience différaient.

Mais l'idée continentale s'inscrit dans la trame historique à un moment précis de l'histoire des Amériques, au moment où les États-Unis commencent à s'étendre sur l'ensemble de leur territoire et au moment où ils formulent un destin manifeste qui vaut plus largement et au-delà de leurs frontières. Quand les propagandistes de la Révolution américaine annoncent le début d'une ère nouvelle pour l'humanité dont l'Amérique sera le berceau ils empruntent le vocabulaire et les structures discursives des théologiens du First Great Awakening, grand mouvement millénariste des années 1740. La mission providentielle des Américains, celle de créer une utopie chrétienne dans le Nouveau Monde, se double alors d'un sens politique, celui de donner la démocratie à l'humanité. Si la croissance rapide de la fédération américaine semble confirmer son rôle historique, le caractère démocratique des États dépend de leur encadrement par la Constitution fédérale, elle-même le produit du "génie démocratique " des Américains. L'essor d'un nationalisme américain plus vigoureux dans les années 1820 s'alimente du succès des révolutions coloniales que la doctrine Monroe met sous le protectorat moral des États-Unis. Simultanément, la République subit les convulsions suscitées par un nouvel enthousiasme évangélique, et le millénarisme renouvelé des années 1820 et 1830 influence à son tour le discours sur le destin et le rôle historique des États-Unis.

Cette ébullition idéologique revivifie le caractère révolutionnaire du républicanisme américain qui s'exprime plus ouvertement dans le discours contestataire des partisans du président Democrat Andrew Jackson. Les jacksoniens s'attaquent à ce qui leur apparait comme les vestiges aristocratiques dans leur république, mais ils ciblent également les régimes monarchiques et leur influence en Amérique. Les rébellions canadiennes éclatent donc dans un contexte idéologique favorable à leur réception, du moins chez les républicains radicaux aux États-Unis. Malgré la politique de neutralité du président Van Buren, la cause des Patriotes attire la sympathie des citoyens au Vermont, mais les appuis se manifestent plus 
concrètement dans l'État de New York. Les Papineau, père et fils, sont reçus par l'élite politique de l'État et leur présence dans les principaux milieux politiques Democrat facilite la communication avec la nouvelle Democratic Review, dirigée par un autre New-yorkais, John L. O'Sullivan. De toute apparence, la United States Democratic Review a tissé des liens serrés avec les exilés patriotes. Ces derniers, dont les Papineau, Wolfred Nelson et Edmund Bailey O'Callaghan la lisent, et y contribuent par de l'information sur le mouvement patriote et les événements survenus au Bas-Canada. Il en résulte une interprétation des Rébellions bas-canadiennes fort sympathique et largement fidèle à celle des exilés eux-mêmes, ou du moins à celle de son chef Louis-Joseph Papineau. En ce sens, la présence des exilés en terre américaine permet de concrétiser une affinité idéologique qui souligne le caractère transnational de la lutte républicaine et anticoloniale. Bien qu'il se garde d'en appeler à la participation active de ses concitoyens dans la lutte pour la libération du Bas-Canada, O'Sullivan situe les rébellions dans le contexte d'un mouvement anticolonial plus large inspiré justement des idéaux républicains et démocratiques des États-Unis. Or, les premières formulations très nettes du manifest destiny paraissent seulement quelques mois après la publication d'articles qu'il avait consacrés à la situation des colonies canadiennes. Le rédacteur de la Democratic Review précisera sa pensée sur le destin hémisphérique des États-Unis entre 1839 et 1845 , et même si la doctrine vise surtout à justifier l'annexion du Texas et des territoires acquis du Mexique, O'Sullivan prédit que les colonies sises sur la frontière septentrionale des États-Unis seront parmi les premières à se joindre, et ce de leur gré, à la grande république continentale en formation.

Il faut noter que les Bas-Canadiens s'approprient l'idée d'un destin manifeste propre sur le continent au début de l'Union; Amédée Papineau commence à formuler l'idée en 1842. C'est qu'au-delà de la marque étatsunienne, le Bas-Canada se cherche un avenir après les rebellions, un avenir dont l'une des figures sera l'annexionnisme en 1849. La prégnance des États-Unis dans l'autoreprésentation du Bas-Canada connaît une intensité nouvelle, la place que le voisin occupe dans le Rapport Durham de 1839 en constituant un signe.

Deux visions de l'insertion continentale du Bas-Canada et du Québec prévalent à compter de l'Union : une vision politique, d'émancipation, républicaine et démocratique, celle d'Amédée Papineau et de son père ; puis une vision culturelle, de conservation de la religion et de la langue chez Étienne Parent. Ces deux visions précèdent d'une dizaine d'années la vision que Rameau de Saint-Père fixe en 1859. Et il faut l'observer, autant dans le cas des Papineau que dans celui de Parent, les visions se formulent pour une bonne part devant l'Institut canadien de Montréal. 
Les sources de ces visions plus ou moins utopiques varient. La vision continentale d'Amédée Papineau se construit en partie dans une dynamique de rapport de force colonial; le fils Papineau est convaincu de l'importance de l'indépendance des sociétés américaines à l'égard des métropoles européennes, d'où sa gageure sur le fait que la question d'Orient pourrait déstabiliser l'Anglerterre et faciliter l'autonomie du Canada-Uni. Chez lui, tout nourrit l'utopie : sa lecture du Tocqueville de La démocratie en Amérique, des deux vastes « confédérations démocratiques " qui se préparent au nord et au sud et seraient une " marche à l'unité "; sa lecture de Lamennais, d'une conjugaison du christianisme et de la démocratie qui nourrit l'évangéliste en lui qui deviendra presbytérien et s'exprimera assez spontanément dans un lexique religieux; sa lecture des écrits d'économie politique où il trouve une idée d'avenir dans l'accroissement des richesses et du développement heureux des sociétés dont les États-Unis sont le modèle.

Depuis 1823, depuis sa discussion avec lord Bathurst qu’il évoquera en 1839 au début de son Histoire de la résistance du Canada au gouvernement anglais, Papineau estime que les colonies britanniques d'Amérique du nord s'émanciperont tôt ou tard comme les autres colonies américaines. Tout comme son fils et ses concitoyens, il est placé en 1845, à son retour d'exil, devant la même question : où est l'avenir après l'échec des luttes constitutionnelles, de la résistance de 1837 , de l'insurrection de 1838, de l'opposition à l'Union et bientôt de l'annexionnisme ? C'est à partir de 1854 que Papineau évoque sa vision continentale qui témoigne de la logique d'une pensée politique admirative des institutions républicaines étatsuniennes depuis le milieu des années 1820 . Son continentalisme indique que s'il garde unis la nationalité et le républicanisme, celui-ci prévaut. Être américain au sens continental du terme, c'est répudier toutes traces de monarchie et être républicain. Et, à vrai dire, s'il y a une trace plus évidente d'utopie dans son continentalisme, c'est dans son discours de 1867 à l'Institut canadien de Montréal.

Étienne Parent, qui dirige Le Canadien de Québec entre 1831 et 1842, journal dont la devise est " Nos institutions, notre langue et nos lois ", estime que ce sont ces signes distincts qui assurent à l'Angleterre son maintien en Amérique du Nord et qui façonnent sa vision des " grands desseins de la providence " sur un peuple au destin moral et intellectuel. La vision de Parent, marquée aussi par l'économie politique, trouve dans la Conquête, dans la victoire de Châteauguay, dans la Confédération et dans l'émigration aux États-Unis de "soldats de Dieu » des signes de ces " grands desseins» de la providence. 
ORIGINES ET FORMES DIVERSES DU « DESTIN MANIFESTE »...

73

Chez Rameau de Saint-Père, intéressé par le développement des colonies de la France et de l'Angleterre, l'image de la France exportée en est une de référence morale et culturelle. Il faut enfin noter que la vision continentale de Parent et de Rameau de Saint-Père sauve la religion et la langue, ce qui n'est pas le cas chez les Papineau qui composent avec la domination continentale de l'anglais et une éventuelle assimilation linguistique tout en plaidant pour un multilinguisme. Puis, il faut retenir l'aveu d'Amédée Papineau qui, hésitant à retourner faire une conférence publique à l'Institut canadien de Montréal en 1859, reconnait que son utopie n’a guère passé depuis 1848 .

Jouis - Meogss thenoy

Hnall eanende 